\title{
Association between multiple comorbidities and self-rated health status in middle-aged and elderly Chinese: the China Kadoorie Biobank study
}

Xingyue Song ${ }^{1}$, Jing $\mathrm{Wu}^{1}$, Canqing $\mathrm{Yu}^{2}$, Wenhong Dong ${ }^{1}$, Jun Lv², Yu Guo ${ }^{3}$, Zheng Bian ${ }^{3}$, Ling Yang ${ }^{4}$,

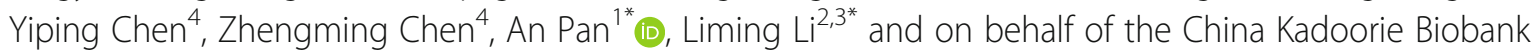
Collaborative Group

\begin{abstract}
Background: Understanding the correlates of self-rated health (SRH) can help public health professionals prioritize health-promotion and disease-prevention interventions. This study aimed to investigate the association between multiple comorbidities and global SRH and age-comparative SRH.

Methods: A total of 512,891 participants aged 30-79 years old were recruited into the China Kadoorie Biobank study from ten regions between 2004 and 2008. Multivariate logistic regression models were used to estimate the odds ratios (ORs) for the associations between comorbidities (including diabetes, hypertension, coronary heart disease, rheumatic heart disease, stroke, tuberculosis, emphysema/bronchitis, asthma, cirrhosis/chronic hepatitis, peptic ulcer, gallbladder disease, kidney disease, fracture, rheumatic arthritis, psychiatric disorders, depressive symptoms, neurasthenia, head injury and cancer) and SRH. Population attributable risks (PARs) were used to estimate the contribution of multiple comorbidities to poor global SRH and worse age-comparative SRH.

Results: After adjusting for covariates, suffering from various diseases increased the chance of reporting a poor global SRH [OR $(95 \% \mathrm{Cl})$ ranged from $1.10(1.07,1.13)$ for fracture to $3.21(2.68,3.83)$ for rheumatic heart disease] and a worse age-comparative SRH [OR $(95 \% \mathrm{Cl})$ ranged from $1.18(1.13,1.23)$ for fracture to $7.56(6.93,8.25)$ for stroke]. From the population perspective, $20.23 \%$ of poor global SRH and $45.12 \%$ of worse age-comparative SRH could attributed to the cardiometabolic diseases, with hypertension (7.84\% for poor global SRH and $13.79 \%$ for worse age-comparative SRH), diabetes (4.35\% for poor global SRH and $10.71 \%$ for worse age-comparative SRH), coronary heart disease $(4.44 \%$ for poor global SRH and $9.51 \%$ for worse age-comparative SRH) and stroke (3.20\% for poor global SRH and $10.19 \%$ for worse age-comparative SRH) making the largest contribution.

(Continued on next page)
\end{abstract}

\footnotetext{
* Correspondence: panan@hust.edu.cn; Imleeph@vip.163.com

${ }^{1}$ Department of Epidemiology and Biostatistics, and Ministry of Education Key Laboratory of Environment and Health, and State Key Laboratory of Environmental Health (Incubating), School of Public Health, Tongji Medical College, Huazhong University of Science and Technology, 13 Hangkong Rd, Wuhan 430030, China

${ }^{2}$ Department of Epidemiology and Biostatistics, School of Public Health,

Peking University Health Science Center, 38 Xueyuan Rd, Beijing 100191,

China

Full list of author information is available at the end of the article
}

(c) The Author(s). 2018 Open Access This article is distributed under the terms of the Creative Commons Attribution 4.0 International License (http://creativecommons.org/licenses/by/4.0/), which permits unrestricted use, distribution, and reproduction in any medium, provided you give appropriate credit to the original author(s) and the source, provide a link to the Creative Commons license, and indicate if changes were made. The Creative Commons Public Domain Dedication waiver (http://creativecommons.org/publicdomain/zero/1.0/) applies to the data made available in this article, unless otherwise stated. 
(Continued from previous page)

Conclusions: Various diseases were major determinants of global and age-comparative SRH, and cardiometabolic diseases had the strongest impact on both global SRH and age-comparative SRH at the population level.

Prevention measures concentrated on these conditions would greatly reduce the total burden of poor SRH and its consequences such as poor quality of life and use of health care services.

Keywords: Comorbidity, Self-rated health status, Cross-sectional study, Chinese population

\section{Background}

Self-rated health (SRH), a common but comprehensive measure of a person's global (physical and mental) health status, has been widely used to describe the health status of an individual and a population in epidemiology surveys because of the easily collected data [1]. Respondents are asked to rate their own health status and there are three types of SRH that are frequently assessed in different studies. The most commonly used one is global $\mathrm{SRH}$, in which respondents are requested to rate their current overall health status on a four- or five-point scale ranging from "very good (excellent)" to "very poor" [2]. In the age-comparative SRH, respondents are asked to rate their health status as better, the same, or worse compared with other people of their ages [3]. As for time-comparative SRH, respondents are asked to compare their present health to the health status a year earlier [4]. $\mathrm{SRH}$ is one of the indicators recommended for health monitoring by the World Health Organization [5], and has been demonstrated to be a powerful predictor of morbidity and mortality in different populations $[2,6,7]$.

Understanding the determinants and correlates of SRH can help public health professionals prioritize the interventions for health promotion and disease prevention. Previous studies have found a wide range of determinants of SRH, including sociodemographic factors, lifestyle factors, physical illness and psychological factors [8-12]. It is widely acknowledged that physical and mental illnesses are major determinants of SRH; however, few studies have comprehensively examined the relations of multiple physical and mental conditions with SRH. Many studies combined various physical illnesses into one variable to explore the association between the presence and/or number of chronic diseases and SRH [9, 13-16]. A few studies examined different chronic diseases as independent variables, but the number of diseases was limited and generally less than eight [17-20]. Only one study conducted in western Sweden has examined eleven chronic diseases and their associations with SRH, but only global SRH was used and the sample size was small $(n=6061)$ [21].

Using data from the China Kadoorie Biobank (CKB) with over half million participants, we aimed to investigate the relations of multiple comorbidities with global SRH and age-comparative SRH among middle-aged and elderly population in China.

\section{Methods \\ Study population}

The CKB study is a general population-based prospective cohort study that was designed to investigate the complex interplay of lifestyle behavior, environmental and genetic factors and risks of various chronic diseases. The detailed study design, sampling strategy and features of the study participants are previously reported [22, 23]. In brief, a total of 512,891 participants aged from 30 to79 years old were recruited from ten regions covering five rural areas (Gansu, Henan, Zhejiang, Sichuan, and Hunan provinces) and five urban cities (Harbin, Qingdao, Suzhou, Liuzhou, and Haikou) in China between 2004 and 2008. The study sites were selected based on population stability, geographic area, quality of death and disease registries, regional patterns of diseases and exposure to specific risk factors, and local commitment and capacity.

In the baseline survey, trained interviewers conducted a standardized questionnaire using a laptop-based direct data-entry system for the questionnaires, with built-in functions to avoid data missing and logical errors. The questionnaires covered general demographic characteristics, socio-economic status, diet, general health, physical activity, family medical history and mental health. After the interview, a series of physical measurements including weight, height, waist and hip circumference and blood pressures were recorded for each participant by trained technicians, and a $10-\mathrm{mL}$ non-fasting blood sample was taken.

We excluded 2 participants with missing values of body weight or height. A total of 512,889 participants (40.99\% male and $59.01 \%$ female) remained in the current analysis.

\section{Exposure variables}

Physician diagnosed disease status was enquired in baseline questionnaire. Respondents were asked: "Has a doctor ever told you that you had the following disease?" followed by a list of diseases including diabetes, hypertension, coronary heart disease (CHD), stroke, rheumatic heart disease, tuberculosis, emphysema/bronchitis, asthma, cirrhosis/chronic hepatitis, peptic ulcer, gallstone/gallbladder disease, kidney disease, fracture, rheumatic arthritis, psychiatric 
disorders, neurasthenia, head injury and cancer. If someone reported that he/she was diagnosed with cancer, the site of cancer was also asked. Prevalent diabetes was defined if the participant met one of the following criteria [24]: 1) self-reported diagnosis of diabetes mellitus; 2) use of anti-diabetic medications; 3) fasting plasma glucose $\geq 7.0 \mathrm{mmol} / \mathrm{L}$; and 4) random blood glucose $\geq 11.1 \mathrm{mmol} / \mathrm{L}$. Prevalent hypertension was defined if the participants met one of the following criteria [25]: 1) systolic blood pressure of $\geq 140 \mathrm{mmHg}$; 2) diastolic blood pressure of $\geq 90 \mathrm{mmHg}$; 3 ) self-reported diagnosis of hypertension; and 4) use of antihypertensive medication. If someone reported that he/she had been diagnosed with a disease, the age at first diagnosis and basic treatment information was also asked. Past year major depression was assessed using the Chinese version of computerized Composite International Diagnostic Inventory - short form (CIDI-SF), and the details were described elsewhere [26].

\section{Outcome variables}

To assess SRH status of each participant, two questions were asked in baseline interview: 1) How is your current general health status: excellent, good, fair, or poor? 2) How is your current health status compared with someone of your own age: better, about the same, worse, or don't know? We considered the first question as global SRH and the second one as age-comparative SRH. No data were missing for two SRH variables. We categorized the global SRH into two categories to be comparable to the literature on this topic: good (excellent, good) and poor (fair, poor). For the age-comparative SRH, participants answering "don't know" ( $n=15,691,3.06 \%)$ were excluded from the analysis. To be consistent with global $\mathrm{SRH}$, participants answering "about the same" $(n=$ $321,218,62.63 \%)$ were excluded in the main analysis and thus age-comparative SRH was categorized into two groups: better and worse. In order to ensure the accuracy and robustness of the results, we also conducted sensitivity analysis of including participants who reported "about the same" and thus age-comparative SRH was categorized into three groups: better, about the same, and worse.

\section{Confounding factors}

Other variables included age, sex, study location (10 regions), marital status (married, widowed, separated/divorced, never married), education level (no formal education, primary, middle or high school, college/university or higher), annual household income $(<10,000$, 10,000-19,999, 20,000-34,999, $\geq 35,000$ RMB), employment status (employed, unemployed and retired), cigarette smoking (never, former, occasionally, current smoker) and alcohol drinking (never, former, occasionally, current drinker) were also inquired in the baseline questionnaires.
Body mass index (BMI) was calculated as weight divided by the square of height $\left(\mathrm{kg} / \mathrm{m}^{2}\right)$. The physical activity level was measured by adding up metabolic equivalent tasks (METs) for daily work or leisure activities. All participants were also inquired about their family history of five diseases, including diabetes, heart attack, stroke, mental disorders and cancer.

\section{Statistical analysis}

Baseline demographic, socioeconomic, behavioral characteristics by global SRH categories and age-comparative SRH groups were presented by unadjusted proportions for categorical variables and unadjusted means with standard deviations (SD) for continuous variables, and compared using ANOVA and Chi-square tests for continuous and categorical variables, respectively. Logistic regression models were used to estimate odds ratios (ORs) and 95\% confidence intervals (CIs) for relations of multiple comorbidities with global and age-comparative $\mathrm{SRH}$. We adjusted for potential confounders in sequential steps: model 1 adjusted for sociodemographic factors (age in continuous variable, sex, study location, marital status, education level, household income and occupation in categorical variable); model 2 further adjusted for lifestyle factors (BMI in continuous variable, cigarette smoking, alcohol drinking, physical activity level and family history of five diseases, in categories); model 3 additionally adjusted for all comorbidities in the same model to test the independent associations. In the sensitivity analysis of including participants answering "about the same" for the age-comparative SRH, multinomial logistic regression models were used.

Population attributable risks (PARs) were used to estimate the proportion of the total prevalence of poor global SRH (or worse age-comparative SRH) that could be attributed to multiple comorbidities, and were calculated for each disease using the following formula: $\mathrm{PAR}=(\mathrm{p}(\mathrm{OR}-1)) /(\mathrm{p}(\mathrm{OR}-1)+1)$ [27], where $\mathrm{p}$ denotes the proportion of participants with the condition in the study population, and OR is the corresponding odds ratio observed in our study.

Stratified analyses were performed according to sex, administrative regions (urban and rural), age (30-59, $\geq 60$ years old), education level (no formal education, primary school, middle school or higher) and household income $(<10,000,10,000-34,999$ and $\geq$ 35,000 RMB). Tests for interaction were conducted by adding interaction terms of the certain disease and the stratifying variable in the final model. We also analyzed the impact of the duration of disease diagnosis, treatment, the number of diseases and the site of cancer on global and age-comparative SRH. Furthermore, to test the influence of undiagnosed diseases on the associations, we used hypertension and diabetes as examples in a sensitivity analysis. In 
the main analysis, the definitions of hypertension and diabetes included both the self-reported physician-diagnosed diseases and screening-detected diseases from the physical examination (which could be considered as undiagnosed cases). In the sensitivity analysis, we only used self-reported physician-diagnosed hypertension and diabetes (yes vs. no) as the exposures and evaluated their associations with SRH. All analyses were performed using SAS 9.3 (SAS Institute Inc), and two-sided $P$ values $<0.05$ were considered as statistical significance.

\section{Results}

The baseline characteristics of participants are presented in Table 1. Of the 512,889 participants, the mean age (standard deviation, SD) was 51.53 (10.68), and 59.01\% $(n=302,631)$ were women. Most participants were married (90.59\%) and more than half $(55.90 \%)$ were recruited from rural areas; two-thirds of the participants were employed (68.74\%), and about one-fourth (26.43\%) were current smokers and $17.13 \%$ were current regular drinkers. The mean (SD) MET and BMI of the participants was 21.08 (13.87) and 23.66 (3.38), respectively.

The most prevalent disease was hypertension $(34.02 \%)$, followed by fracture (6.91\%), gallstone/gallbladder disease (6.04\%), diabetes (5.91\%), peptic ulcer (3.90\%), CHD (3.02\%), emphysema/bronchitis (2.59\%), rheumatoid arthritis $(2.07 \%)$, stroke $(1.73 \%)$, cirrhosis/chronic hepatitis (1.21\%), tuberculosis (1.49\%), kidney disease (1.48\%), neurasthenia (1.11\%), head injury $(1.10 \%)$, depressive symptoms $(0.64 \%)$, asthma $(0.55 \%)$, cancer $(0.50 \%)$, psychiatric disorders $(0.37 \%)$ and rheumatic heart disease (0.18\%) (Table 1).

Table 2 shows the associations between various diseases and global SRH. In the final multivariate model, suffering from any of the diseases increased the chance of reporting a poor global SRH, the OR $(95 \% \mathrm{CI})$ ranged from $1.10(1.07,1.13)$ for fracture to $3.21(2.68,3.83)$ for rheumatic heart disease. Similar findings were obtained in the stratified analyses, while the magnitude of the association between some diseases and global SRH was significantly stronger in one stratum than the other (Appendix Tables 5-7).

Table 3 shows the associations between various diseases and age-comparative SRH. In the final multivariate model, similarly, all diseases were associated with higher odds of a worse age-comparative SRH: the OR $(95 \% \mathrm{CI})$ ranged from $1.18(1.13,1.23)$ for fracture to $7.56(6.93,8.25)$ for stroke. Similar findings were obtained in the stratified analyses (Appendix Tables 8-10). Stroke remained to have the strongest association in certain subgroups (rural residence, male, age subgroups, all education levels and low household income groups). In the sensitivity analysis of including participants who answered "about the same", the results did not change materially either using better as the reference group (Appendix Tables 11) or using "about the same" as the reference group (Appendix Tables 12): people with multiple comorbidities were less likely to report better age-comparative SRH while more likely to report worse age-comparative SRH.

From the population perspective, cardiometabolic diseases (hypertension, diabetes, CHD, and stroke), explained the largest part of poor global SRH and worse age-comparative SRH in our study population, followed by emphysema/bronchitis and gallstone/gallbladder disease. Whereas the contribution of rheumatic heart diseases, psychiatric disorders and cancer was small because of the low prevalence (Table 4).

We further examined whether treatment would affect $\mathrm{SRH}$, the results suggested that people with diseases and still on treatment tended to report a poor global SRH and worse age-comparative SRH compared with those having a disease but not receiving treatment (Appendix Table 13). For diabetes and hypertension, shorter duration was associated with less worse SRH, while for other diseases, longer duration was associated with a much worse global and age-comparative SRH (Appendix Table 14). Compared with people without any diseases, the OR for poor global SRH was 1.44 for having one disease, 2.37 and 3.91 for two and three diseases, respectively, and 6.45 when four or more diseases were present $(P$ for trend $<0.001$; Appendix Table 15). For worse age-comparative SRH, the corresponding OR was $2.13,5.15,10.50$, and 20.39 for one, two, three and four or more diseases ( $P$ for trend <0.001; Appendix Table 15).

When looking at different types of cancer, liver cancer had the greatest impact on global SRH (OR: 3.85; 95\% CI: $1.48,10.01)$, followed by lung cancer, stomach cancer, other cancer types, intestine cancer, breast cancer, cervix cancer and esophagus cancer. For age-comparative SRH, esophagus cancer had the greatest impact (OR: 8.94; 95\% CI: 5.43, 14.74), followed by lung cancer, stomach cancer, other cancer types, liver cancer, breast cancer, intestine cancer and cervix cancer (Appendix Table 16).

When examining the influence of undiagnosed diseases on the association, we found that the association become stronger in the sensitivity analysis of using self-reported hypertension and diabetes compared to the main analysis of using both self-reported and screening-detected (i.e., undiagnosed) hypertension and diabetes (Appendix Table 17).

\section{Discussion}

In this large population-based prospective study, we found that having multiple diseases significantly increased the chance of reporting a poor global SRH and a worse age-comparative $\mathrm{SRH}$, although the magnitude of different diseases varied substantially. We also found cardiometabolic diseases (hypertension, diabetes, CHD 


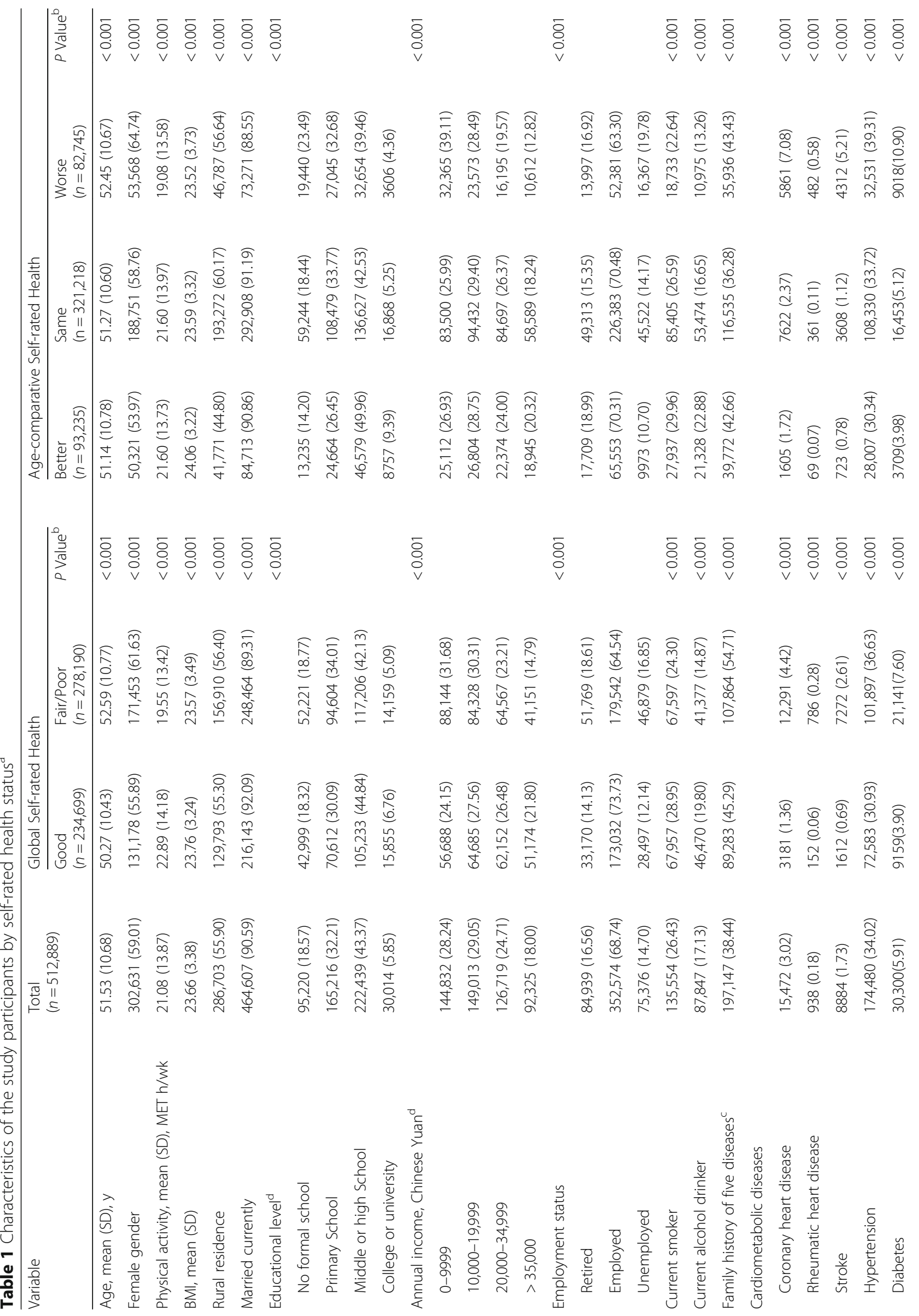




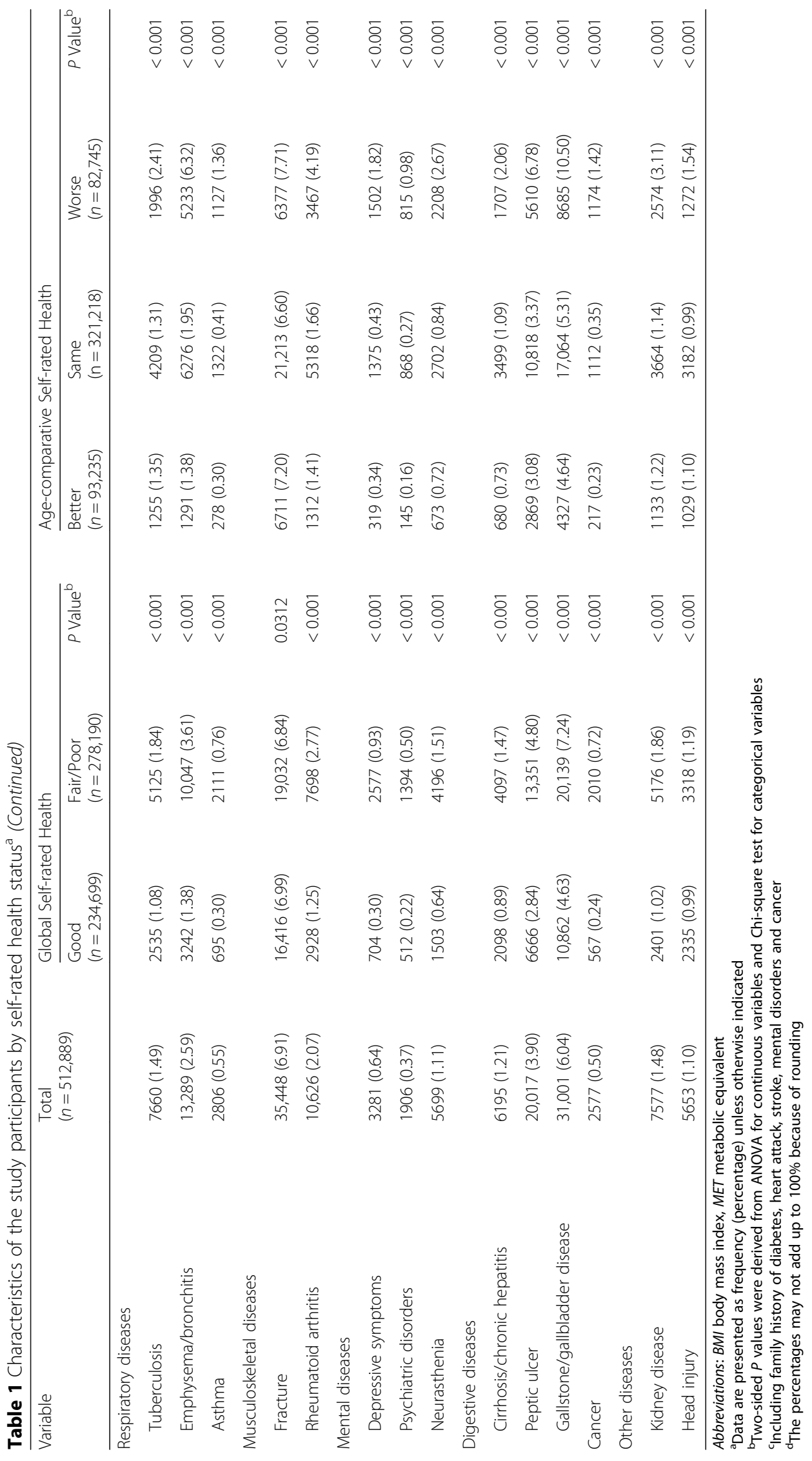


Table 2 Multiple comorbidities associated with global self-rated health status

\begin{tabular}{|c|c|c|c|c|c|c|}
\hline & \multicolumn{2}{|c|}{ Model $1^{\mathrm{a}}$} & \multicolumn{2}{|c|}{ Model $2^{b}$} & \multicolumn{2}{|c|}{ Model $3^{c}$} \\
\hline & $\overline{O R}$ & $95 \% \mathrm{Cl}$ & $\overline{O R}$ & $95 \% \mathrm{Cl}$ & $\overline{O R}$ & $95 \% \mathrm{Cl}$ \\
\hline \multicolumn{7}{|l|}{ Cardiometabolic diseases } \\
\hline Coronary heart disease & 2.91 & $2.79,3.03$ & 2.87 & $2.75,2.99$ & 2.54 & $2.43,2.65$ \\
\hline Rheumatic heart disease & 3.74 & $3.14,4.46$ & 3.59 & $3.01,4.28$ & 3.21 & $2.68,3.83$ \\
\hline Stroke & 3.30 & $3.12,3.49$ & 3.10 & $2.93,3.28$ & 2.91 & $2.74,3.07$ \\
\hline Hypertension & 1.24 & $1.22,1.26$ & 1.28 & $1.26,1.29$ & 1.25 & $1.23,1.26$ \\
\hline Diabetes & 1.86 & $1.81,1.91$ & 1.85 & $1.80,1.89$ & 1.77 & $1.72,1.82$ \\
\hline \multicolumn{7}{|l|}{ Respiratory diseases } \\
\hline Tuberculosis & 1.58 & $1.50,1.66$ & 1.54 & $1.46,1.61$ & 1.48 & $1.41,1.56$ \\
\hline Emphysema/bronchitis & 2.65 & $2.55,2.77$ & 2.57 & $2.46,2.67$ & 2.47 & $2.37,2.58$ \\
\hline Asthma & 2.55 & $2.33,2.78$ & 2.48 & $2.27,2.71$ & 2.05 & $1.87,2.24$ \\
\hline \multicolumn{7}{|l|}{ Musculoskeletal diseases } \\
\hline Fracture & 1.11 & $1.08,1.14$ & 1.12 & $1.09,1.15$ & 1.10 & $1.07,1.13$ \\
\hline Rheumatoid arthritis & 1.99 & $1.90,2.08$ & 1.99 & $1.90,2.08$ & 1.83 & $1.75,1.92$ \\
\hline \multicolumn{7}{|l|}{ Mental disease } \\
\hline Depressive Symptoms & 3.09 & $2.83,3.36$ & 3.01 & $2.76,3.28$ & 2.66 & $2.44,2.90$ \\
\hline Psychiatric disorders & 2.52 & $2.27,2.79$ & 2.45 & $2.20,2.71$ & 2.16 & $1.94,2.40$ \\
\hline Neurasthenia & 2.52 & $2.37,2.67$ & 2.47 & $2.33,2.63$ & 2.14 & $2.01,2.27$ \\
\hline \multicolumn{7}{|l|}{ Digestive diseases } \\
\hline Cirrhosis/chronic hepatitis & 1.80 & $1.71,1.90$ & 1.72 & $1.63,1.82$ & 1.67 & $1.58,1.77$ \\
\hline Peptic ulcer & 1.78 & $1.72,1.83$ & 1.72 & $1.67,1.78$ & 1.69 & $1.64,1.75$ \\
\hline Gallstone/gallbladder disease & 1.69 & $1.65,1.73$ & 1.68 & $1.63,1.72$ & 1.59 & $1.55,1.64$ \\
\hline Cancer & 2.65 & $2.41,2.91$ & 2.43 & $2.21,2.67$ & 2.56 & $2.33,2.82$ \\
\hline \multicolumn{7}{|l|}{ Other diseases } \\
\hline Kidney disease & 1.81 & $1.72,1.90$ & 1.78 & $1.70,1.88$ & 1.63 & $1.55,1.72$ \\
\hline Head injury & 1.23 & $1.17,1.30$ & 1.24 & $1.17,1.31$ & 1.19 & $1.12,1.26$ \\
\hline
\end{tabular}

Abbreviations: $\mathrm{Cl}$ confidence intervals, $\mathrm{OR}$ odds ratio

${ }^{a}$ Model 1: adjusted for age, sex, study location, marital status, education level, income and occupation

${ }^{\mathrm{b}}$ Model 2: model 1 plus cigarette smoking, alcohol drinking, physical activity, BMI and family history of five disease (stroke, heart attack, diabetes, mental disorders and cancer)

${ }^{\mathrm{c}}$ Model 3: model 2 plus all comorbidities in the same mode

and stroke) had the strongest impact on both global $\mathrm{SRH}$ and age-comparative SRH at the population level.

Overall, presence of cardiovascular disease (CHD, stroke and rheumatic heart disease) had the biggest impact on global SRH. Other diseases that have a great impact on global SRH including respiratory disease (emphysema/bronchitis and asthma), mental disorders and cancer (adjusted ORs were all above 2.00). Consistent with our findings, Haseli-Mashhadi et al. [20] found that cardiovascular disease had the strongest impact on global SRH in a study of 3289 middle-aged and elderly Chinese adults. Some other studies in different populations also found that cardiovascular disease, cancer and mental diseases were the major determinants of global SRH $[19,21,28,29]$.

In general, the associations between diseases and age-comparative SRH were stronger than the associations with global SRH. Consistently, cardiovascular disease, cancer and mental diseases had the major impact on reporting worse age-comparative SRH. Our findings are consistent with some other studies which found that chronic diseases substantially affected people's perception of their health status compared to their peers of similar age. In our study, stroke was the most important factor affecting age-comparative SRH among total population, rural residence and male participants. A study in Sweden also found that stroke had the biggest impact on reporting worse age-comparative SRH [18], while a study in Hong Kong found that depressive symptoms was the most significant factor associated with worse age-comparative SRH [17].

Chronic disease like $\mathrm{CHD}$, stroke, rheumatic heart disease, cancer, and emphysema or bronchitis have a great influence on people's functional ability, which in turn is significantly associated with both global and age-comparative 
Table 3 Multiple comorbidities associated with age-comparative self-rated health status ${ }^{\mathrm{a}}$

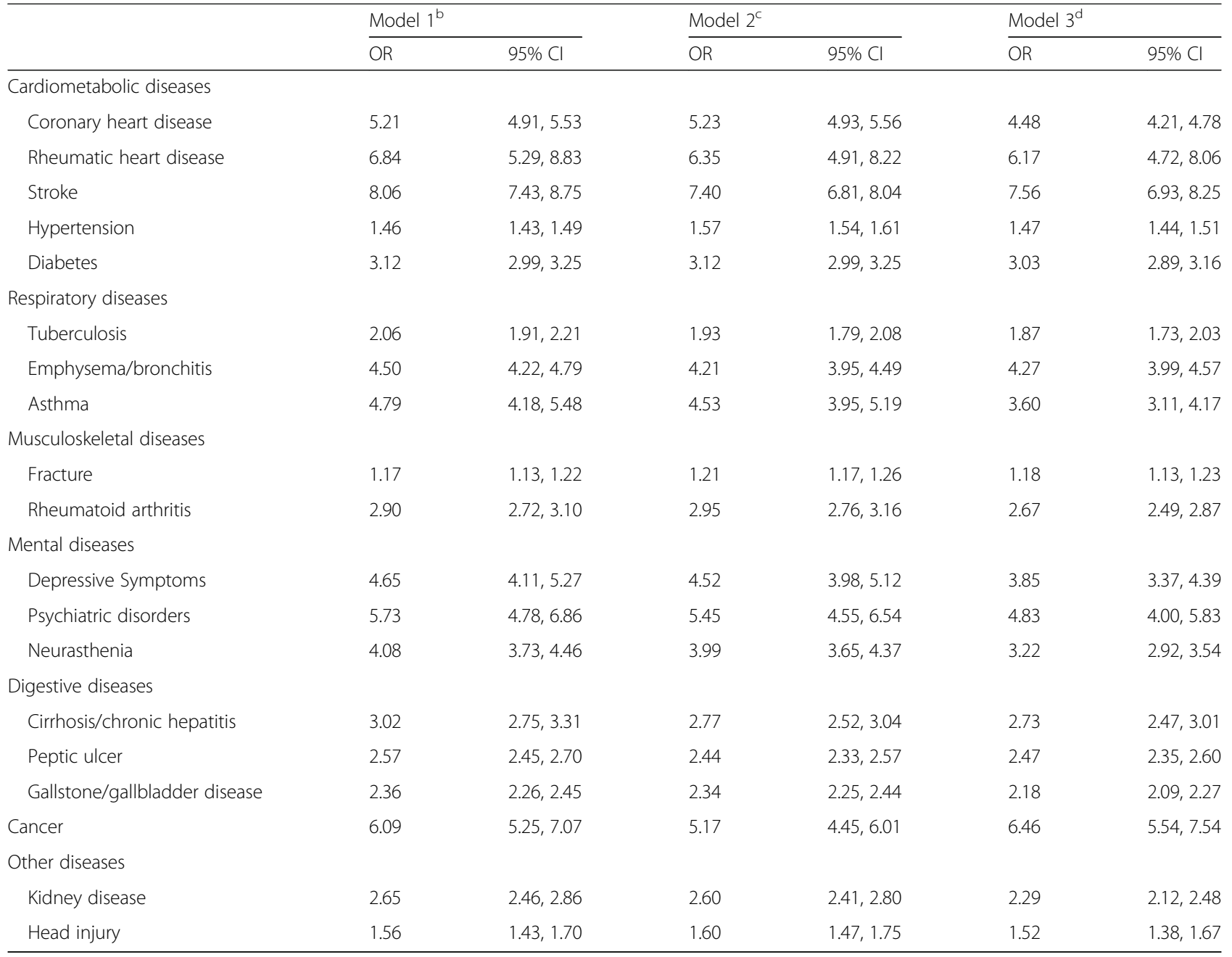

Abbreviations: $\mathrm{Cl}$ confidence intervals, $O R$ odds ratio

aParticipants answering "don't know" ( $n=15,691)$ and "about the same" ( $n=321,218)$ for the age-comparative self-rated health status question were excluded from the analysis, leaving 175,980 participants in this analysis

${ }^{\mathrm{b}}$ Model 1: adjusted for age, sex, study location, marital status, education level, income and occupation

"Model 2: model 1 plus cigarette smoking, alcohol drinking, physical activity, BMI and family history of five disease (stroke, heart attack, diabetes, mental disorders and cancer)

${ }^{\mathrm{d}}$ Model 3: model 2 plus all comorbidities in the same model

SRH $[3,15,17]$. Meanwhile, people with chronic diseases can experience pain and disability that results in poor SRH. Depression was another important factor affecting both global and age-comparative SRH in our study: people who are more depressed are more inclined to rate their health more negatively, which is consistent with previous studies [30-32].

In our population of middle-aged and elderly men and women, hypertension had the strongest impact on both global SRH and age-comparative SRH at the population level. The contributions of diabetes, $\mathrm{CHD}$ and stroke to the burden of poor global SRH and worse age- comparative SRH were also large due to either high prevalence rates or large effect size. However, it should be noted that the population level contribution of different diseases may vary in populations with different prevalence rates.

We found that people with diseases and still on treatment generally reported worse SRH compared to those with a disease but not receiving treatment, which might be because people still on treatment had worse disease status or had more serious conditions. In our study, longer duration was associated with much worse SRH for diabetes and hypertension, and this may be because longer duration of diabetes and hypertension was associated with higher risks of complications, cardiovascular and cerebrovascular diseases [33-35]. In addition, the number of comorbidities was significantly associated with worse SRH, which is in line with the literature [14, 15, 36]. People with more diseases have increased possibility of dysfunction and suffer more pain 
Table 4 Population attributable risks for poor self-rated health by multiple comorbidities ${ }^{a}$

\begin{tabular}{|c|c|c|c|c|}
\hline & \multicolumn{2}{|c|}{ Global SRH (Total $n=512,889$ ) } & \multicolumn{2}{|c|}{ Age-comparative SRH (Total $n=175,980$ ) } \\
\hline & PAR & $95 \% \mathrm{Cl}$ & PAR & $95 \% \mathrm{Cl}$ \\
\hline \multicolumn{5}{|l|}{ Cardiometabolic diseases } \\
\hline Coronary heart disease & 4.44 & $4.14,4.75$ & 9.51 & $8.84,10.25$ \\
\hline Rheumatic heart disease & 0.40 & $0.30,0.51$ & 0.92 & $0.67,1.25$ \\
\hline Stroke & 3.20 & $2.92,3.46$ & 10.19 & $9.30,11.14$ \\
\hline Hypertension & 7.84 & $7.26,8.13$ & 13.79 & $13.02,14.78$ \\
\hline Diabetes & 4.35 & $4.08,4.62$ & 10.71 & $10.05,11.32$ \\
\hline \multicolumn{5}{|l|}{ Respiratory diseases } \\
\hline Tuberculosis & 0.71 & $0.61,0.83$ & 1.28 & $1.08,1.51$ \\
\hline Emphysema/bronchitis & 3.67 & $3.43,3.93$ & 7.81 & $7.19,8.46$ \\
\hline Asthma & 0.57 & $0.48,0.68$ & 1.41 & $1.15,1.71$ \\
\hline \multicolumn{5}{|l|}{ Musculoskeletal diseases } \\
\hline Fracture & 0.69 & $0.48,0.89$ & 1.23 & $0.89,1.56$ \\
\hline Rheumatoid arthritis & 1.69 & $1.53,1.87$ & 3.34 & $2.99,3.73$ \\
\hline \multicolumn{5}{|l|}{ Mental diseases } \\
\hline Depressive Symptoms & 1.05 & $0.91,1.20$ & 1.79 & $1.49,2.12$ \\
\hline Psychiatric disorders & 0.43 & $0.35,0.52$ & 1.40 & $1.10,1.76$ \\
\hline Neurasthenia & 1.25 & $1.11,1.39$ & 2.40 & $2.09,2.74$ \\
\hline \multicolumn{5}{|l|}{ Digestive diseases } \\
\hline Cirrhosis/chronic hepatitis & 0.80 & $0.70,0.92$ & 2.05 & $1.75,2.37$ \\
\hline Peptic ulcer & 2.62 & $2.44,2.84$ & 5.42 & $5.00,5.87$ \\
\hline Gallstone/gallbladder disease & 3.44 & $3.22,3.72$ & 6.65 & $6.18,7.12$ \\
\hline Cancer & 0.77 & $0.66,0.90$ & 2.66 & $2.22,3.17$ \\
\hline \multicolumn{5}{|l|}{ Other diseases } \\
\hline Kidney disease & 0.92 & $0.81,1.05$ & 1.87 & $1.63,2.14$ \\
\hline Head injury & 0.21 & $0.13,0.29$ & 0.57 & $0.42,0.73$ \\
\hline
\end{tabular}

Abbreviations: $\mathrm{Cl}$ confidence intervals, PAR population attributable risks

a Note that the prevalences of these diseases and symptoms overlap and therefore the population attributable risks cannot be summed up but should be considered as relative

and inconvenience both physically and mentally, which can lead them to rate their health more negatively.

The major strength of our study is that we have covered a wide range of diseases and the analysis was based on a large population sample of both men and women in ten regions of China. We also included both global and age-comparative SRH measures in our study, and the large sample size allowed us to conduct stratified analyses with sufficient power. Many of the previous studies have only studied the contribution of diseases on global SRH at individual level, whereas we studied the contribution of diseases on both global and age-comparative $\mathrm{SRH}$ at both the individual and population level. However, the study has several limitations that should be noted. The main limitation is the cross-sectional design of the study, which does not allow for investigating the temporal associations between various diseases and SRH. Another limitation is that most of the studied diseases were self-reported which may be subject to misclassifications. The sensitivity analysis of using self-reported hypertension and diabetes vs. the main analysis of using both self-reported and screening-detected cases indicated that this type of misclassification might overestimate the association. This is probably because people with self-reported physician-diagnosed diseases were more likely to be severe cases, and thus the association would be attenuated if we included both self-reported and undiagnosed diseases in the analysis. However, the magnitude of attenuation may depend on the proportion of undiagnosed cases. For hypertension and diabetes, the proportion of undiagnosed cases was not negligible, in other words, the awareness of the disease was not very high in the Chinese populations $[37,38]$. While for other diseases (such as heart diseases, stroke, cancer etc.), the proportion might be very high and the influence of the undiagnosed diseases would not substantially change our conclusions. In addition, although 
we have adjusted for a wide range of confounding factors such as socioeconomic, demographic and behavioral variables, residual and unmeasured confounding is still possible. For example, functional ability and/or cognitive levels, which have been previously found to be associated with SRH $[3,15,39]$, were not available in our study. Finally, detailed information on treatment and severity status of each disease was not available and more studies are still needed to examine strategies to promote better SRH among people with certain diseases.

\section{Conclusions}

We found chronic physical diseases (such as cardiovascular disease, diabetes, cancer) and mental illnesses are major determinants of poor global SRH and worse age-comparative SRH. Cardiometabolic diseases (hypertension, diabetes, CHD and stroke) had the strongest impact on both global SRH and age-comparative SRH at the population level. Our study suggests that prevention measures concentrated on these conditions would have the largest effect on the total burden of poor SRH and its consequences such as poor quality of life and use of health care services. Knowledge of diseases that have a great impact on both global SRH and age-comparative SRH might help in exploring the factors behind low SRH status. Knowing the patient's SRH status and the common determinants of SRH could help health professionals in the health care sectors to focus on the patient's own goals for health and function.

\section{Appendix}

Table 5 Multiple comorbidities associated with global self-rated health stratified by residential location and sex

\begin{tabular}{|c|c|c|c|c|c|c|c|c|c|c|}
\hline & \multicolumn{4}{|c|}{ Administrative region } & \multirow{3}{*}{$\begin{array}{l}P \text { for } \\
\text { interaction }\end{array}$} & \multicolumn{4}{|l|}{ Sex } & \multirow{3}{*}{$\begin{array}{l}P \text { for } \\
\text { interaction }\end{array}$} \\
\hline & \multicolumn{2}{|l|}{ Rural } & \multicolumn{2}{|c|}{ Urban } & & \multicolumn{2}{|l|}{ Male } & \multicolumn{2}{|c|}{ Female } & \\
\hline & $\overline{\mathrm{OR}}$ & $95 \% \mathrm{Cl}$ & $\overline{O R}$ & $95 \% \mathrm{Cl}$ & & $\overline{\mathrm{OR}}$ & $95 \% \mathrm{Cl}$ & $\overline{\mathrm{OR}}$ & $95 \% \mathrm{Cl}$ & \\
\hline \multicolumn{11}{|l|}{ Cardiometabolic diseases } \\
\hline Coronary heart disease & 2.75 & $2.55,2.96$ & 2.34 & $2.22,2.46$ & $<0.001$ & 2.57 & $2.41,2.75$ & 2.50 & $2.37,2.64$ & 0.12 \\
\hline Rheumatic heart disease & 3.63 & $2.82,4.67$ & 2.62 & $2.03,3.37$ & 0.07 & 4.41 & $2.99,6.49$ & 2.86 & $2.33,3.50$ & 0.07 \\
\hline Stroke & 2.92 & $2.67,3.20$ & 2.69 & $2.50,2.89$ & 0.02 & 3.16 & $2.93,3.40$ & 2.69 & $2.46,2.93$ & 0.23 \\
\hline Hypertension & 1.15 & $1.13,1.17$ & 1.22 & $1.20,1.25$ & 0.006 & 1.24 & $1.22,1.27$ & 1.24 & $1.22,1.27$ & 0.01 \\
\hline Diabetes & 1.64 & $1.57,1.71$ & 1.83 & $1.77,1.90$ & 0.007 & 1.90 & $1.82,1.98$ & 1.69 & $1.63,1.75$ & 0.006 \\
\hline \multicolumn{11}{|l|}{ Respiratory diseases } \\
\hline Tuberculosis & 1.60 & $1.48,1.73$ & 1.37 & $1.28,1.47$ & $<0.001$ & 1.55 & $1.45,1.66$ & 1.40 & $1.30,1.51$ & 0.31 \\
\hline Emphysema/bronchitis & 2.87 & $2.71,3.05$ & 1.81 & $1.70,1.92$ & $<0.001$ & 2.49 & $2.34,2.64$ & 2.45 & $2.31,2.60$ & 0.99 \\
\hline Asthma & 1.89 & $1.63,2.20$ & 2.16 & $1.93,2.41$ & 0.69 & 2.05 & $1.78,2.35$ & 2.05 & $1.81,2.31$ & 0.81 \\
\hline \multicolumn{11}{|l|}{ Musculoskeletal diseases } \\
\hline Fracture & 1.09 & $1.06,1.13$ & 1.01 & $0.98,1.04$ & $<0.001$ & 1.09 & $1.05,1.12$ & 1.10 & $1.07,1.14$ & 0.88 \\
\hline Rheumatoid arthritis & 1.82 & $1.70,1.94$ & 1.91 & $1.80,2.03$ & 0.80 & 1.71 & $1.58,1.85$ & 1.87 & $1.77,1.97$ & 0.008 \\
\hline \multicolumn{11}{|l|}{ Mental diseases } \\
\hline Depressive Symptoms & 2.50 & $2.24,2.78$ & 2.49 & $2.16,2.89$ & 0.53 & 2.60 & $2.22,3.05$ & 2.70 & $2.44,3.00$ & 0.98 \\
\hline Psychiatric disorders & 1.94 & $1.68,2.24$ & 1.88 & $1.62,2.19$ & 0.68 & 2.40 & $1.97,2.93$ & 2.04 & $1.79,2.31$ & 0.10 \\
\hline Neurasthenia & 2.00 & $1.82,2.19$ & 1.91 & $1.75,2.07$ & 0.22 & 1.90 & $1.70,2.13$ & 2.23 & $2.07,2.41$ & 0.005 \\
\hline \multicolumn{11}{|l|}{ Digestive diseases } \\
\hline Cirrhosis/chronic hepatitis & 1.56 & $1.45,1.68$ & 1.89 & $1.74,2.06$ & $<0.001$ & 1.70 & $1.59,1.83$ & 1.58 & $1.45,1.73$ & 0.07 \\
\hline Peptic ulcer & 1.80 & $1.72,1.89$ & 1.61 & $1.55,1.68$ & $<0.001$ & 1.57 & $1.50,1.63$ & 1.89 & $1.80,1.99$ & $<0.001$ \\
\hline Gallstone/gallbladder disease & 1.57 & $1.51,1.62$ & 1.37 & $1.32,1.42$ & $<0.001$ & 1.52 & $1.45,1.60$ & 1.61 & $1.56,1.66$ & 0.004 \\
\hline Cancer & 2.09 & $1.81,2.40$ & 2.71 & $2.37,3.09$ & 0.01 & 2.99 & $2.54,3.51$ & 2.31 & $2.05,2.61$ & 0.02 \\
\hline \multicolumn{11}{|l|}{ Other diseases } \\
\hline Kidney disease & 1.75 & $1.63,1.88$ & 1.40 & $1.30,1.51$ & $<0.001$ & 1.50 & $1.38,1.63$ & 1.72 & $1.61,1.84$ & $<0.001$ \\
\hline Head injury & 1.26 & $1.17,1.37$ & 1.20 & $1.11,1.30$ & 0.10 & 1.19 & $1.11,1.28$ & 1.20 & $1.09,1.31$ & 0.81 \\
\hline
\end{tabular}

Abbreviations: $\mathrm{Cl}$ confidence intervals, $O R$ odds ratio

Odds ratios $(95 \% \mathrm{Cl})$ were calculated after adjustment of age, sex, study location, marital status, household income, education level, occupation, alcohol drinking, cigarette smoking, physical activity, BMI, family history of five diseases (stroke, heart attack, diabetes, mental disorders and cancer) and all comorbidities, except for the stratified variable in the corresponding stratified analysis 
Table 6 Multiple comorbidities associated with global self-rated health stratified by age and educational level

\begin{tabular}{|c|c|c|c|c|c|c|c|c|c|c|c|c|}
\hline & \multicolumn{4}{|l|}{ Age } & \multirow{3}{*}{$\begin{array}{l}P \text { for } \\
\text { interaction }\end{array}$} & \multicolumn{6}{|c|}{ Education level } & \multirow{3}{*}{$\begin{array}{l}P \text { for } \\
\text { interaction }\end{array}$} \\
\hline & \multicolumn{2}{|c|}{$30-59 \mathrm{yr}$} & \multicolumn{2}{|c|}{$\geq 60 \mathrm{yr}$} & & \multicolumn{2}{|c|}{$\begin{array}{l}\text { No formal } \\
\text { education }\end{array}$} & \multicolumn{2}{|c|}{ Primary school } & \multicolumn{2}{|c|}{$\begin{array}{l}\text { Middle school or } \\
\text { higher }\end{array}$} & \\
\hline & $\overline{\mathrm{OR}}$ & $95 \% \mathrm{Cl}$ & $\overline{\mathrm{OR}}$ & $95 \% \mathrm{Cl}$ & & $\overline{\mathrm{OR}}$ & $95 \% \mathrm{Cl}$ & $\overline{\mathrm{OR}}$ & $95 \% \mathrm{Cl}$ & $\overline{\mathrm{OR}}$ & $95 \% \mathrm{Cl}$ & \\
\hline \multicolumn{13}{|l|}{ Cardiometabolic diseases } \\
\hline Coronary heart disease & 3.03 & $2.84,3.24$ & 2.50 & $2.37,2.64$ & $<0.001$ & 2.42 & $2.18,2.70$ & 2.59 & $2.40,2.80$ & 2.56 & $2.42,2.71$ & 0.79 \\
\hline Rheumatic heart disease & 3.06 & $2.47,3.78$ & 3.68 & $2.62,5.16$ & 0.55 & 3.12 & $2.12,4.58$ & 3.57 & $2.52,5.03$ & 3.01 & $2.34,3.87$ & 0.71 \\
\hline Stroke & 3.33 & $3.04,3.65$ & 2.98 & $2.77,3.21$ & $<0.001$ & 3.08 & $2.68,3.54$ & 2.92 & $2.64,3.23$ & 2.94 & $2.72,3.19$ & 0.40 \\
\hline Hypertension & 1.27 & $1.25,1.29$ & 1.19 & $1.16,1.22$ & $<0.001$ & 1.14 & $1.11,1.18$ & 1.21 & $1.18,1.23$ & 1.32 & $1.29,1.34$ & $<0.001$ \\
\hline Diabetes & 1.83 & $1.76,1.89$ & 1.71 & $1.64,1.79$ & $<0.001$ & 1.70 & $1.61,1.81$ & 1.67 & $1.59,1.75$ & 1.88 & $1.81,1.96$ & $<0.001$ \\
\hline \multicolumn{13}{|l|}{ Respiratory diseases } \\
\hline Tuberculosis & 1.67 & $1.56,1.79$ & 1.35 & $1.25,1.46$ & $<0.001$ & 1.70 & $1.46,1.98$ & 1.45 & $1.32,1.60$ & 1.47 & $1.37,1.57$ & 0.10 \\
\hline Emphysema/bronchitis & 2.66 & $2.51,2.81$ & 2.27 & $2.13,2.42$ & $<0.001$ & 2.79 & $2.55,3.04$ & 2.77 & $2.57,2.97$ & 2.04 & $1.91,2.18$ & $<0.001$ \\
\hline Asthma & 2.16 & $1.93,2.41$ & 1.92 & $1.64,2.25$ & 0.04 & 1.86 & $1.51,2.30$ & 2.02 & $1.70,2.42$ & 2.14 & $1.89,2.42$ & 0.66 \\
\hline \multicolumn{13}{|l|}{ Musculoskeletal diseases } \\
\hline Fracture & 1.10 & $1.07,1.13$ & 1.09 & $1.05,1.15$ & 0.03 & 1.25 & $1.18,1.31$ & 1.10 & $1.05,1.15$ & 1.05 & $1.02,1.09$ & 0.06 \\
\hline Rheumatoid arthritis & 1.97 & $1.87,2.09$ & 1.58 & $1.47,1.71$ & $<0.001$ & 1.83 & $1.66,2.02$ & 1.77 & $1.63,1.92$ & 1.87 & $1.75,2.00$ & 0.58 \\
\hline \multicolumn{13}{|l|}{ Mental diseases } \\
\hline Depressive Symptoms & 2.58 & $2.34,2.84$ & 2.71 & $2.20,3.34$ & 0.93 & 2.83 & $2.34,3.42$ & 2.52 & $2.17,2.92$ & 2.67 & $2.35,3.05$ & 0.55 \\
\hline Psychiatric disorders & 2.28 & $2.02,2.58$ & 1.75 & $1.40,2.19$ & 0.002 & 2.34 & $1.90,2.88$ & 2.02 & $1.68,2.44$ & 2.24 & $1.90,2.65$ & 0.39 \\
\hline Neurasthenia & 2.42 & $2.24,2.61$ & 1.64 & $1.47,1.83$ & $<0.001$ & 2.39 & $2.07,2.76$ & 2.13 & $1.89,2.41$ & 2.06 & $1.90,2.25$ & 0.72 \\
\hline \multicolumn{13}{|l|}{ Digestive diseases } \\
\hline Cirrhosis/chronic hepatitis & 1.81 & $1.70,1.93$ & 1.40 & $1.24,1.57$ & $<0.001$ & 1.55 & $1.33,1.80$ & 1.67 & $1.51,1.85$ & 1.72 & $1.60,1.86$ & 0.69 \\
\hline Peptic ulcer & 1.82 & $1.76,1.89$ & 1.40 & $1.32,1.49$ & $<0.001$ & 1.81 & $1.67,1.96$ & 1.74 & $1.64,1.85$ & 1.63 & $1.56,1.70$ & 0.04 \\
\hline Gallstone/gallbladder disease & 1.69 & $1.64,1.74$ & 1.40 & $1.33,1.47$ & $<0.001$ & 1.64 & $1.56,1.73$ & 1.63 & $1.56,1.71$ & 1.54 & $1.48,1.59$ & 0.12 \\
\hline Cancer & 2.79 & $2.46,3.17$ & 2.41 & $2.08,2.81$ & 0.004 & 2.70 & $2.15,3.40$ & 2.45 & $2.07,2.89$ & 2.62 & $2.28,3.01$ & 0.73 \\
\hline \multicolumn{13}{|l|}{ Other diseases } \\
\hline Kidney disease & 1.70 & $1.61,1.81$ & 1.48 & $1.33,1.64$ & $<0.001$ & 1.83 & $1.58,2.13$ & 1.68 & $1.52,1.85$ & 1.57 & $1.47,1.68$ & 0.16 \\
\hline Head injury & 1.21 & $1.13,1.29$ & 1.04 & $0.92,1.18$ & 0.001 & 1.26 & $1.07,1.48$ & 1.24 & $1.12,1.37$ & 1.15 & $1.07,1.24$ & 0.49 \\
\hline
\end{tabular}

Abbreviations: $\mathrm{Cl}$ confidence intervals, $O R$ odds ratio

Odds ratios $(95 \% \mathrm{Cl})$ were calculated after adjustment of age, sex, study location, marital status, household income, education level, occupation, alcohol drinking, cigarette smoking, physical activity, BMI, family history of five diseases (stroke, heart attack, diabetes, mental disorders and cancer) and all comorbidities, except for the stratified variable in the corresponding stratified analysis 
Table 7 Multiple comorbidities associated with global self-rated health stratified by household income

\begin{tabular}{|c|c|c|c|c|c|c|c|}
\hline & \multicolumn{6}{|c|}{ Household income, RMB } & \multirow{3}{*}{$\begin{array}{l}P \text { for } \\
\text { interaction }\end{array}$} \\
\hline & \multicolumn{2}{|c|}{$<10,000$} & \multicolumn{2}{|c|}{$10,000-34,999$} & \multicolumn{2}{|c|}{$\geq 35,000$} & \\
\hline & $\overline{\mathrm{OR}}$ & $95 \% \mathrm{Cl}$ & $\overline{O R}$ & $95 \% \mathrm{Cl}$ & $\overline{\mathrm{OR}}$ & $95 \% \mathrm{Cl}$ & \\
\hline \multicolumn{8}{|l|}{ Cardiometabolic diseases } \\
\hline Coronary heart disease & 2.51 & $2.29,2.76$ & 2.53 & $2.40,2.68$ & 2.52 & $2.30,2.77$ & 0.86 \\
\hline Rheumatic heart disease & 2.41 & $1.81,3.19$ & 3.80 & $2.91,4.97$ & 3.64 & $2.30,5.75$ & 0.09 \\
\hline Stroke & 3.24 & $2.89,3.62$ & 2.79 & $2.59,3.01$ & 2.77 & $2.41,3.18$ & 0.60 \\
\hline Hypertension & 1.19 & $1.16,1.22$ & 1.25 & $1.23,1.28$ & 1.32 & $1.28,1.37$ & $<0.001$ \\
\hline Diabetes & 1.71 & $1.61,1.81$ & 1.74 & $1.68,1.80$ & 1.87 & $1.77,1.99$ & 0.001 \\
\hline \multicolumn{8}{|l|}{ Respiratory diseases } \\
\hline Tuberculosis & 1.71 & $1.54,1.89$ & 1.41 & $1.32,1.51$ & 1.41 & $1.26,1.58$ & 0.01 \\
\hline Emphysema/bronchitis & 2.75 & $2.53,2.99$ & 2.39 & $2.25,2.54$ & 2.35 & $2.15,2.56$ & 0.08 \\
\hline Asthma & 1.98 & $1.62,2.43$ & 2.05 & $1.81,2.31$ & 2.11 & $1.75,2.54$ & 0.78 \\
\hline \multicolumn{8}{|l|}{ Musculoskeletal diseases } \\
\hline Fracture & 1.14 & $1.08,1.20$ & 1.08 & $1.04,1.11$ & 1.10 & $1.05,1.15$ & 0.04 \\
\hline Rheumatoid arthritis & 1.81 & $1.66,1.97$ & 1.83 & $1.72,1.95$ & 1.85 & $1.67,2.06$ & 0.65 \\
\hline \multicolumn{8}{|l|}{ Mental diseases } \\
\hline Depressive Symptoms & 2.98 & $2.56,3.47$ & 2.55 & $2.26,2.87$ & 2.27 & $1.78,2.89$ & 0.10 \\
\hline Psychiatric disorders & 2.31 & $1.91,2.78$ & 2.14 & $1.84,2.48$ & 2.08 & $1.60,2.70$ & 0.86 \\
\hline Neurasthenia & 2.00 & $1.75,2.28$ & 2.18 & $2.00,2.37$ & 2.25 & $1.97,2.56$ & 0.07 \\
\hline \multicolumn{8}{|l|}{ Digestive diseases } \\
\hline Cirrhosis/chronic hepatitis & 1.83 & $1.62,2.06$ & 1.72 & $1.59,1.86$ & 1.51 & $1.35,1.68$ & 0.008 \\
\hline Peptic ulcer & 1.92 & $1.80,2.04$ & 1.66 & $1.59,1.74$ & 1.50 & $1.40,1.61$ & $<0.001$ \\
\hline Gallstone/gallbladder disease & 1.71 & $1.63,1.81$ & 1.57 & $1.51,1.62$ & 1.52 & $1.45,1.60$ & 0.003 \\
\hline Cancer & 1.93 & $1.62,2.30$ & 2.63 & $2.31,3.00$ & 3.92 & $3.07,5.01$ & $<0.001$ \\
\hline \multicolumn{8}{|l|}{ Other diseases } \\
\hline Kidney disease & 1.71 & $1.55,1.88$ & 1.62 & $1.51,1.74$ & 1.54 & $1.36,1.73$ & 0.16 \\
\hline Head injury & 1.35 & $1.21,1.50$ & 1.11 & $1.03,1.20$ & 1.17 & $1.03,1.34$ & 0.02 \\
\hline
\end{tabular}

Abbreviations: $\mathrm{Cl}$ confidence intervals, $O R$ odds ratio

Odds ratios $(95 \% \mathrm{Cl})$ were calculated after adjustment of age, sex, study location, marital status, household income, education level, occupation, alcohol drinking, cigarette smoking, physical activity, BMI, family history of five diseases (stroke, heart attack, diabetes, mental disorders and cancer) and all comorbidities, except for the stratified variable in the corresponding stratified analysis 
Table 8 Multiple comorbidities associated with age-comparative self-rated health stratified by residential location and sex ${ }^{\mathrm{a}}$

\begin{tabular}{|c|c|c|c|c|c|c|c|c|c|c|}
\hline & \multicolumn{4}{|c|}{ Administrative region } & \multirow{3}{*}{$\begin{array}{l}P \text { for } \\
\text { interaction }\end{array}$} & \multicolumn{4}{|l|}{ Sex } & \multirow{3}{*}{$\begin{array}{l}P \text { for } \\
\text { interaction }\end{array}$} \\
\hline & \multicolumn{2}{|l|}{ Rural } & \multicolumn{2}{|c|}{ Urban } & & \multicolumn{2}{|l|}{ Male } & \multicolumn{2}{|c|}{ Female } & \\
\hline & OR & $95 \% \mathrm{Cl}$ & OR & $95 \% \mathrm{Cl}$ & & OR & $95 \% \mathrm{Cl}$ & OR & $95 \% \mathrm{Cl}$ & \\
\hline \multicolumn{11}{|l|}{ Cardiometabolic diseases } \\
\hline Coronary heart disease & 5.62 & $4.92,6.43$ & 4.20 & $3.90,4.53$ & $<0.001$ & 4.96 & $4.47,5.49$ & 4.24 & $3.91,4.60$ & 0.37 \\
\hline Rheumatic heart disease & 6.96 & $4.66,10.38$ & 5.37 & $3.74,7.72$ & 0.29 & 7.06 & $4.03,12.36$ & 5.81 & $4.29,7.86$ & 0.66 \\
\hline Stroke & 9.40 & $7.98,11.06$ & 6.29 & $5.66,6.97$ & $<0.001$ & 10.21 & $9.08,11.48$ & 5.50 & $4.82,6.26$ & $<0.001$ \\
\hline Hypertension & 1.40 & $1.35,1.45$ & 1.53 & $1.48,1.58$ & 0.001 & 1.44 & $1.39,1.50$ & 1.49 & $1.45,1.54$ & $<0.001$ \\
\hline Diabetes & 2.82 & $2.61,3.05$ & 3.18 & $3.01,3.36$ & 0.30 & 3.41 & $3.17,3.66$ & 2.80 & $2.64,2.96$ & 0.07 \\
\hline \multicolumn{11}{|l|}{ Respiratory diseases } \\
\hline Tuberculosis & 2.23 & $1.95,2.56$ & 1.65 & $1.49,1.83$ & $<0.001$ & 1.88 & $1.68,2.11$ & 1.82 & $1.62,2.06$ & 0.94 \\
\hline Emphysema/bronchitis & 6.35 & $5.71,7.06$ & 3.16 & $2.88,3.46$ & $<0.001$ & 4.38 & $3.97,4.82$ & 4.19 & $3.81,4.61$ & 0.99 \\
\hline Asthma & 3.24 & $2.49,4.21$ & 4.30 & $3.62,5.11$ & 0.40 & 3.57 & $2.87,4.44$ & 3.59 & $2.95,4.37$ & 0.92 \\
\hline \multicolumn{11}{|l|}{ Musculoskeletal diseases } \\
\hline Fracture & 1.23 & $1.15,1.31$ & 1.23 & $1.17,1.29$ & 0.11 & 1.18 & $1.12,1.26$ & 1.16 & $1.09,1.23$ & 0.52 \\
\hline Rheumatoid arthritis & 2.76 & $2.48,3.08$ & 2.69 & $2.45,2.96$ & 0.14 & 2.37 & $2.08,2.69$ & 2.79 & $2.56,3.04$ & 0.002 \\
\hline \multicolumn{11}{|l|}{ Mental diseases } \\
\hline Depressive Symptoms & 3.45 & $2.91,4.09$ & 4.48 & $3.66,5.48$ & 0.04 & 3.77 & $3.00,4.75$ & 3.91 & $3.33,4.59$ & 0.88 \\
\hline Psychiatric disorders & 4.51 & $3.44,5.90$ & 5.17 & $3.98,6.72$ & 0.32 & 5.65 & $3.93,8.13$ & 4.48 & $3.59,5.58$ & 0.29 \\
\hline Neurasthenia & 3.35 & $2.88,3.90$ & 3.16 & $2.79,3.57$ & 0.25 & 2.61 & $2.19,3.11$ & 3.50 & $3.12,3.93$ & 0.001 \\
\hline \multicolumn{11}{|l|}{ Digestive diseases } \\
\hline Cirrhosis/chronic hepatitis & 3.00 & $2.61,3.44$ & 2.85 & $2.48,3.28$ & 0.96 & 3.04 & $2.68,3.46$ & 2.28 & $1.95,2.66$ & 0.004 \\
\hline Peptic ulcer & 3.15 & $2.91,3.40$ & 2.09 & $1.95,2.23$ & $<0.001$ & 2.21 & $2.06,2.37$ & 2.82 & $2.61,3.05$ & $<0.001$ \\
\hline Gallstone/gallbladder disease & 2.37 & $2.22,2.53$ & 2.10 & $1.99,2.22$ & $<0.001$ & 2.02 & $1.86,2.19$ & 2.20 & $2.09,2.31$ & 0.001 \\
\hline Cancer & 5.10 & $3.98,6.53$ & 7.20 & $5.92,8.76$ & 0.07 & 8.67 & $6.62,11.35$ & 5.33 & $4.41,6.44$ & 0.007 \\
\hline \multicolumn{11}{|l|}{ Other diseases } \\
\hline Kidney disease & 2.36 & $2.11,2.63$ & 2.32 & $2.07,2.60$ & 0.98 & 2.18 & $1.91,2.50$ & 2.38 & $2.15,2.63$ & 0.09 \\
\hline Head injury & 1.59 & $1.39,1.83$ & 1.47 & $1.30,1.66$ & 0.83 & 1.45 & $1.29,1.64$ & 1.62 & $1.39,1.88$ & 0.28 \\
\hline
\end{tabular}

Abbreviations: $\mathrm{Cl}$ confidence intervals, $\mathrm{OR}$ odds ratio

aparticipants answering "don't know" ( $n=15,691)$ and "about the same" $(n=321,218)$ for the age-comparative self-rated health status question were excluded from the analysis, leaving 175,980 participants in this analysis.

Odds ratios $(95 \% \mathrm{Cl})$ were calculated after adjustment of age, sex, study location, marital status, household income, education level, occupation, alcohol drinking, cigarette smoking, physical activity, BMI, family history of five diseases (stroke, heart attack, diabetes, mental disorders and cancer) and all comorbidities, except for the stratified variable in the corresponding stratified analysis 
Table 9 Multiple comorbidities associated with age-comparative self-rated health stratified by age and educational level ${ }^{a}$

\begin{tabular}{|c|c|c|c|c|c|c|c|c|c|c|c|c|}
\hline & \multicolumn{4}{|l|}{ Age } & \multirow{3}{*}{$\begin{array}{l}P \text { for } \\
\text { interaction }\end{array}$} & \multicolumn{6}{|c|}{ Education level } & \multirow{3}{*}{$\begin{array}{l}P \text { for } \\
\text { interaction }\end{array}$} \\
\hline & \multicolumn{2}{|c|}{$30-59 \mathrm{yr}$} & \multicolumn{2}{|c|}{$\geq 60 \mathrm{yr}$} & & \multicolumn{2}{|c|}{$\begin{array}{l}\text { No formal } \\
\text { education }\end{array}$} & \multicolumn{2}{|c|}{ Primary school } & \multirow{2}{*}{\multicolumn{2}{|c|}{$\begin{array}{l}\text { Middle school or } \\
\text { higher }\end{array}$}} & \\
\hline & $\mathrm{OR}$ & $95 \% \mathrm{Cl}$ & $\mathrm{OR}$ & $95 \% \mathrm{Cl}$ & & $\mathrm{OR}$ & $95 \% \mathrm{Cl}$ & OR & $95 \% \mathrm{Cl}$ & & & \\
\hline \multicolumn{13}{|l|}{ Cardiometabolic diseases } \\
\hline Coronary heart disease & 6.55 & $5.89,7.29$ & 4.01 & $3.68,4.38$ & $<0.001$ & 3.48 & $2.92,4.14$ & 5.32 & $4.68,6.06$ & 4.68 & $4.30,5.08$ & 0.03 \\
\hline Rheumatic heart disease & 6.31 & $4.55,8.74$ & 5.21 & $3.24,8.39$ & 0.56 & 5.78 & $3.05,10.97$ & 4.69 & $2.96,7.43$ & 7.71 & $5.27,11.28$ & 0.39 \\
\hline Stroke & 9.54 & $8.22,11.07$ & 7.92 & $7.07,8.88$ & $<0.001$ & 8.04 & $6.33,10.22$ & 8.02 & $6.81,9.43$ & 7.96 & $7.09,8.94$ & 0.78 \\
\hline Hypertension & 1.42 & $1.38,1.46$ & 1.29 & $1.23,1.35$ & 0.07 & 1.30 & $1.24,1.37$ & 1.40 & $1.34,1.47$ & 1.57 & $1.52,1.63$ & 0.007 \\
\hline Diabetes & 3.19 & $3.01,3.39$ & 2.68 & $2.49,2.88$ & $<0.001$ & 2.60 & $2.34,2.88$ & 2.79 & $2.56,3.03$ & 3.42 & $3.21,3.63$ & $<0.001$ \\
\hline \multicolumn{13}{|l|}{ Respiratory diseases } \\
\hline Tuberculosis & 2.34 & $2.10,2.61$ & 1.46 & $1.28,1.66$ & $<0.001$ & 2.52 & $1.96,3.25$ & 1.83 & $1.56,2.15$ & 1.85 & $1.66,2.05$ & 0.03 \\
\hline Emphysema/bronchitis & 4.63 & $4.22,5.08$ & 3.67 & $3.31,4.07$ & 0.001 & 4.37 & $3.76,5.07$ & 5.16 & $4.59,5.81$ & 3.48 & $3.14,3.85$ & $<0.001$ \\
\hline Asthma & 3.96 & $3.30,4.74$ & 3.18 & $2.47,4.09$ & 0.06 & 3.67 & $2.39,5.64$ & 2.63 & $1.98,3.50$ & 4.26 & $3.55,5.13$ & 0.15 \\
\hline \multicolumn{13}{|l|}{ Musculoskeletal diseases } \\
\hline Fracture & 1.18 & $1.13,1.24$ & 1.12 & $1.03,1.22$ & 0.003 & 1.33 & $1.21,1.46$ & 1.11 & $1.03,1.20$ & 1.18 & $1.11,1.25$ & 0.38 \\
\hline Rheumatoid arthritis & 3.04 & $2.78,3.32$ & 1.98 & $1.75,2.24$ & $<0.001$ & 2.42 & $2.06,2.85$ & 2.67 & $2.35,3.04$ & 2.81 & $2.54,3.10$ & 0.67 \\
\hline \multicolumn{13}{|l|}{ Mental diseases } \\
\hline Depressive Symptoms & 4.01 & $3.46,4.65$ & 3.13 & $2.33,4.22$ & 0.02 & 3.66 & $2.70,4.95$ & 3.62 & $2.83,4.61$ & 4.17 & $3.48,5.01$ & 0.25 \\
\hline Psychiatric disorders & 5.68 & $4.53,7.11$ & 3.46 & $2.39,5.01$ & 0.002 & 4.34 & $2.97,6.35$ & 3.88 & $2.80,5.38$ & 5.82 & $4.37,7.77$ & 0.07 \\
\hline Neurasthenia & 4.07 & $3.61,4.58$ & 1.89 & $1.59,2.25$ & $<0.001$ & 3.71 & $2.85,4.85$ & 2.94 & $2.43,3.57$ & 3.25 & $2.88,3.67$ & 0.45 \\
\hline \multicolumn{13}{|l|}{ Digestive diseases } \\
\hline Cirrhosis/chronic hepatitis & 3.16 & $2.82,3.55$ & 2.13 & $1.75,2.60$ & $<0.001$ & 2.68 & $2.00,3.59$ & 2.86 & $2.36,3.48$ & 2.71 & $2.39,3.07$ & 0.80 \\
\hline Peptic ulcer & 2.74 & $2.57,2.91$ & 1.85 & $1.67,2.04$ & $<0.001$ & 2.70 & $2.34,3.10$ & 2.57 & $2.34,2.83$ & 2.40 & $2.24,2.56$ & 0.07 \\
\hline Gallstone/gallbladder disease & 2.37 & $2.25,2.50$ & 1.68 & $1.55,1.82$ & $<0.001$ & 2.26 & $2.05,2.48$ & 2.17 & $2.00,2.36$ & 2.14 & $2.01,2.27$ & 0.04 \\
\hline Cancer & 7.69 & $6.19,9.56$ & 5.38 & $4.28,6.76$ & 0.002 & 4.48 & $3.13,6.41$ & 6.96 & $5.19,9.34$ & 7.16 & $5.80,8.85$ & 0.04 \\
\hline \multicolumn{13}{|l|}{ Other diseases } \\
\hline Kidney disease & 2.49 & $2.27,2.73$ & 1.92 & $1.63,2.26$ & $<0.001$ & 2.07 & $1.64,2.61$ & 2.19 & $1.89,2.55$ & 2.40 & $2.17,2.66$ & 0.35 \\
\hline Head injury & 1.54 & $1.39,1.71$ & 1.44 & $1.16,1.77$ & 0.06 & 1.70 & $1.29,2.22$ & 1.65 & $1.39,1.96$ & 1.42 & $1.26,1.60$ & 0.42 \\
\hline
\end{tabular}

Abbreviations: $\mathrm{Cl}$ confidence intervals, $\mathrm{OR}$ odds ratio

aparticipants answering "don't know" $(n=15,691)$ and "about the same" $(n=321,218)$ for the age-comparative self-rated health status question were excluded from the analysis, leaving 175,980 participants in this analysis

Odds ratios $(95 \% \mathrm{Cl})$ were calculated after adjustment of age, sex, study location, marital status, household income, education level, occupation, alcohol drinking, cigarette smoking, physical activity, BMI, family history of five diseases (stroke, heart attack, diabetes, mental disorders and cancer) and all comorbidities, except for the stratified variable in the corresponding stratified analysis 
Table 10 Multiple comorbidities associated with age-comparative self-rated health stratified by household income ${ }^{a}$

\begin{tabular}{|c|c|c|c|c|c|c|c|}
\hline & \multicolumn{6}{|c|}{ Household income, RMB } & \multirow{3}{*}{$\begin{array}{l}P \text { for } \\
\text { interaction }\end{array}$} \\
\hline & \multicolumn{2}{|c|}{$<10,000$} & \multicolumn{2}{|c|}{$10,000-34,999$} & \multicolumn{2}{|c|}{$\geq 35,000$} & \\
\hline & OR & $95 \% \mathrm{Cl}$ & OR & $95 \% \mathrm{Cl}$ & OR & $95 \% \mathrm{Cl}$ & \\
\hline \multicolumn{8}{|l|}{ Cardiometabolic diseases } \\
\hline Coronary heart disease & 4.47 & $3.88,5.16$ & 4.56 & $4.20,4.96$ & 4.36 & $3.77,5.04$ & 0.37 \\
\hline Rheumatic heart disease & 4.61 & $3.07,6.92$ & 6.33 & $4.30,9.30$ & 14.13 & $6.12,32.62$ & 0.08 \\
\hline Stroke & 8.32 & $7.00,9.88$ & 7.32 & $6.53,8.21$ & 7.29 & $5.87,9.05$ & 0.97 \\
\hline Hypertension & 1.35 & $1.29,1.41$ & 1.50 & $1.45,1.55$ & 1.69 & $1.58,1.79$ & $<0.001$ \\
\hline Diabetes & 2.67 & $2.44,2.91$ & 3.04 & $2.87,3.23$ & 3.41 & $3.07,3.78$ & $<0.001$ \\
\hline \multicolumn{8}{|l|}{ Respiratory diseases } \\
\hline Tuberculosis & 2.40 & $2.05,2.81$ & 1.71 & $1.52,1.91$ & 1.68 & $1.38,2.04$ & $<0.001$ \\
\hline Emphysema/bronchitis & 4.60 & $4.07,5.20$ & 4.22 & $3.83,4.65$ & 3.89 & $3.35,4.51$ & 0.04 \\
\hline Asthma & 2.78 & $2.05,3.77$ & 3.82 & $3.14,4.65$ & 4.19 & $3.08,5.71$ & 0.19 \\
\hline \multicolumn{8}{|l|}{ Musculoskeletal diseases } \\
\hline Fracture & 1.19 & $1.09,1.30$ & 1.17 & $1.11,1.24$ & 1.18 & $1.08,1.29$ & 0.69 \\
\hline Rheumatoid arthritis & 2.36 & $2.08,2.68$ & 2.90 & $2.62,3.20$ & 2.58 & $2.17,3.07$ & 0.06 \\
\hline \multicolumn{8}{|l|}{ Mental diseases } \\
\hline Depressive Symptoms & 4.12 & $3.33,5.10$ & 3.64 & $3.02,4.39$ & 4.16 & $2.84,6.07$ & 0.72 \\
\hline Psychiatric disorders & 4.32 & $3.17,5.88$ & 4.86 & $3.72,6.36$ & 6.75 & $4.07,11.18$ & 0.15 \\
\hline Neurasthenia & 2.79 & $2.28,3.41$ & 3.32 & $2.92,3.77$ & 3.55 & $2.89,4.36$ & 0.06 \\
\hline \multicolumn{8}{|l|}{ Digestive diseases } \\
\hline Cirrhosis/chronic hepatitis & 2.50 & $2.08,2.99$ & 2.88 & $2.51,3.32$ & 2.81 & $2.26,3.49$ & 0.57 \\
\hline Peptic ulcer & 2.72 & $2.47,3.00$ & 2.42 & $2.26,2.60$ & 2.23 & $1.98,2.51$ & 0.04 \\
\hline Gallstone/gallbladder disease & 2.26 & $2.09,2.45$ & 2.09 & $1.96,2.21$ & 2.31 & $2.10,2.53$ & 0.03 \\
\hline Cancer & 5.30 & $3.98,7.08$ & 6.21 & $5.05,7.63$ & 10.32 & $7.03,15.15$ & 0.02 \\
\hline \multicolumn{8}{|l|}{ Other diseases } \\
\hline Kidney disease & 2.07 & $1.81,2.37$ & 2.48 & $2.21,2.78$ & 2.31 & $1.89,2.82$ & 0.31 \\
\hline Head injury & 1.56 & $1.32,1.84$ & 1.54 & $1.35,1.75$ & 1.36 & $1.08,1.71$ & 0.71 \\
\hline
\end{tabular}

Abbreviations: $\mathrm{Cl}$ confidence intervals, $O R$ odds ratio

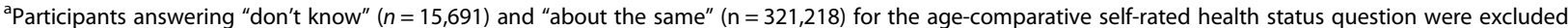
from the analysis, leaving 175,980 participants in this analysis

Odds ratios $(95 \% \mathrm{Cl})$ were calculated after adjustment of age, sex, study location, marital status, household income, education level, occupation, alcohol drinking, cigarette smoking, physical activity, BMI, family history of five diseases (stroke, heart attack, diabetes, mental disorders and cancer) and all comorbidities, except for the stratified variable in the corresponding stratified analysis 
Table 11 Multiple comorbidities associated with age-comparative self-rated health status: multinomial logistic regression analysis using "better" as the reference group ${ }^{a}$

\begin{tabular}{|c|c|c|c|c|c|}
\hline & \multirow{2}{*}{$\begin{array}{l}\text { Better } \\
\text { OR }\end{array}$} & \multicolumn{2}{|c|}{ About the same } & \multicolumn{2}{|c|}{ Worse } \\
\hline & & $\overline{\mathrm{OR}}$ & $95 \% \mathrm{Cl}$ & $\overline{\mathrm{OR}}$ & $95 \% \mathrm{Cl}$ \\
\hline \multicolumn{6}{|l|}{ Cardiometabolic diseases } \\
\hline Coronary heart disease & 1 & 1.65 & $1.56,1.75$ & 4.44 & $4.17,4.72$ \\
\hline Rheumatic heart disease & 1 & 1.52 & $1.17,1.98$ & 5.97 & $4.59,7.76$ \\
\hline Stroke & 1 & 1.80 & $1.66,1.96$ & 7.42 & $6.82,8.07$ \\
\hline Hypertension & 1 & 1.18 & $1.16,1.20$ & 1.48 & $1.45,1.51$ \\
\hline Diabetes & 1 & 1.44 & $1.39,1.50$ & 2.99 & $2.87,3.12$ \\
\hline \multicolumn{6}{|l|}{ Respiratory diseases } \\
\hline Tuberculosis & 1 & 1.17 & $1.09,1.25$ & 1.89 & $1.75,2.04$ \\
\hline Emphysema/bronchitis & 1 & 1.49 & $1.40,1.58$ & 4.35 & $4.07,4.64$ \\
\hline Asthma & 1 & 1.36 & $1.19,1.56$ & 3.43 & $2.98,3.94$ \\
\hline \multicolumn{6}{|l|}{ Musculoskeletal diseases } \\
\hline Fracture & 1 & 0.99 & $0.96,1.02$ & 1.18 & $1.14,1.23$ \\
\hline Rheumatoid arthritis & 1 & 1.26 & $1.18,1.34$ & 2.65 & $2.48,2.84$ \\
\hline \multicolumn{6}{|l|}{ Mental diseases } \\
\hline Depressive Symptoms & 1 & 1.06 & $0.94,1.21$ & 3.71 & $3.26,4.21$ \\
\hline Psychiatric disorders & 1 & 1.80 & $1.51,2.16$ & 4.72 & $3.93,5.67$ \\
\hline Neurasthenia & 1 & 1.35 & $1.24,1.47$ & 3.22 & $2.94,3.54$ \\
\hline \multicolumn{6}{|l|}{ Digestive diseases } \\
\hline Cirrhosis/chronic hepatitis & 1 & 1.33 & $1.22,1.45$ & 2.63 & $2.39,2.89$ \\
\hline Peptic ulcer & 1 & 1.36 & $1.30,1.42$ & 2.48 & $2.36,2.61$ \\
\hline Gallstone/gallbladder disease & 1 & 1.30 & $1.26,1.35$ & 2.16 & $2.07,2.25$ \\
\hline Cancer & 1 & 1.64 & $1.41,1.90$ & 6.44 & $5.54,7.49$ \\
\hline \multicolumn{6}{|l|}{ Other diseases } \\
\hline Kidney disease & 1 & 1.27 & $1.18,1.36$ & 2.36 & $2.19,2.55$ \\
\hline Head injury & 1 & 1.03 & $0.96,1.11$ & 1.53 & $1.40,1.67$ \\
\hline
\end{tabular}

Abbreviations: $\mathrm{Cl}$ confidence intervals, $\mathrm{OR}$ odds ratio

a Participants answering "don't know" ( $n=15,691)$ for the age-comparative self-rated health status question were excluded from the analysis, leaving 497,198 participants in this analysis

Odds ratios $(95 \% \mathrm{Cl})$ were calculated after adjustment of age, sex, study location, marital status, household income, education level, occupation, alcohol drinking, cigarette smoking, physical activity, BMI, family history of five diseases (stroke, heart attack, diabetes, mental disorders and cancer) and all comorbidities 
Table 12 Multiple comorbidities associated with age-comparative self-rated health status: multinomial logistic regression analysis using "about the same" as the reference group ${ }^{a}$

\begin{tabular}{|c|c|c|c|c|c|}
\hline & \multirow{2}{*}{$\begin{array}{l}\text { About the same } \\
\text { OR }\end{array}$} & \multicolumn{2}{|c|}{ Better } & \multicolumn{2}{|c|}{ Worse } \\
\hline & & $\mathrm{OR}$ & $95 \% \mathrm{Cl}$ & $\mathrm{OR}$ & $95 \% \mathrm{Cl}$ \\
\hline \multicolumn{6}{|l|}{ Cardiometabolic diseases } \\
\hline Coronary heart disease & 1 & 0.61 & $0.57,0.64$ & 2.69 & $2.59,2.80$ \\
\hline Rheumatic heart disease & 1 & 0.66 & $0.51,0.85$ & 3.92 & $3.38,4.55$ \\
\hline Stroke & 1 & 0.56 & $0.51,0.60$ & 4.12 & $3.92,4.33$ \\
\hline Hypertension & 1 & 0.85 & $0.83,0.86$ & 1.25 & $1.23,1.28$ \\
\hline Diabetes & 1 & 0.70 & $0.67,0.72$ & 2.08 & $2.02,2.14$ \\
\hline \multicolumn{6}{|l|}{ Respiratory diseases } \\
\hline Tuberculosis & 1 & 0.86 & $0.80,0.92$ & 1.62 & $1.53,1.72$ \\
\hline Emphysema/bronchitis & 1 & 0.67 & $0.63,0.72$ & 2.93 & $2.81,3.05$ \\
\hline Asthma & 1 & 0.74 & $0.64,0.84$ & 2.52 & $2.30,2.75$ \\
\hline \multicolumn{6}{|l|}{ Musculoskeletal diseases } \\
\hline Fracture & 1 & 1.01 & $0.98,1.04$ & 1.19 & $1.15,1.23$ \\
\hline Rheumatoid arthritis & 1 & 0.79 & $0.75,0.84$ & 2.10 & $2.00,2.21$ \\
\hline \multicolumn{6}{|l|}{ Mental diseases } \\
\hline Depressive Symptoms & 1 & 0.94 & $0.83,1.07$ & 3.49 & $3.22,3.78$ \\
\hline Psychiatric disorders & 1 & 0.56 & $0.46,0.66$ & 2.62 & $2.36,2.91$ \\
\hline Neurasthenia & 1 & 0.74 & $0.68,0.81$ & 2.39 & $2.25,2.55$ \\
\hline \multicolumn{6}{|l|}{ Digestive diseases } \\
\hline Cirrhosis/chronic hepatitis & 1 & 0.75 & $0.69,0.82$ & 1.97 & $1.85,2.10$ \\
\hline Peptic ulcer & 1 & 0.74 & $0.71,0.77$ & 1.83 & $1.76,1.90$ \\
\hline Gallstone/gallbladder disease & 1 & 0.77 & $0.74,0.80$ & 1.61 & $1.61,1.71$ \\
\hline Cancer & 1 & 0.61 & $0.53,0.71$ & 3.93 & $3.60,4.29$ \\
\hline \multicolumn{6}{|l|}{ Other diseases } \\
\hline Kidney disease & 1 & 0.79 & $0.74,0.85$ & 1.86 & $1.76,1.97$ \\
\hline Head injury & 1 & 0.97 & $0.90,1.05$ & 1.49 & $1.39,1.60$ \\
\hline
\end{tabular}

Abbreviations: $\mathrm{Cl}$ confidence intervals, $O R$ odds ratio

a Participants answering "don't know" ( $n=15,691)$ for the age-comparative self-rated health status question were excluded from the analysis, leaving 497,198 participants in this analysis

Odds ratios $(95 \% \mathrm{Cl})$ were calculated after adjustment of age, sex, study location, marital status, household income, education level, occupation, alcohol drinking, cigarette smoking, physical activity, BMI, family history of five diseases (stroke, heart attack, diabetes, mental disorders and cancer) and all comorbidities 
Table 13 Treatment associated with self-rated health status

\begin{tabular}{|c|c|c|c|c|}
\hline \multirow{2}{*}{ 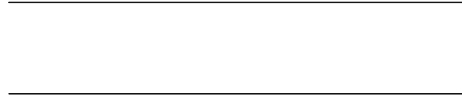 } & \multicolumn{2}{|c|}{ Global SRH (Total $n=512,889$ ) } & \multicolumn{2}{|c|}{ Age-comparative SRH (Total $n=175,980$ ) } \\
\hline & $\overline{\mathrm{OR}}$ & $95 \% \mathrm{Cl}$ & $\overline{\mathrm{OR}}$ & $95 \% \mathrm{Cl}$ \\
\hline \multicolumn{5}{|l|}{ Cardiometabolic diseases } \\
\hline \multicolumn{5}{|l|}{ Coronary heart disease } \\
\hline Yes, but no treatment now & 1.85 & $1.75,1.96$ & 2.79 & $2.55,3.06$ \\
\hline Yes, still on treatment & 2.91 & $2.73,3.09$ & 5.32 & $4.85,5.83$ \\
\hline \multicolumn{5}{|l|}{ Rheumatic heart disease } \\
\hline Yes, but no treatment now & 2.27 & $1.84,2.80$ & 3.67 & $2.68,5.05$ \\
\hline Yes, still on treatment & 7.33 & $5.01,10.72$ & 19.27 & $10.65,34.87$ \\
\hline \multicolumn{5}{|l|}{ Stroke } \\
\hline Yes, but no treatment now & 2.12 & $1.96,2.28$ & 4.25 & $3.78,4.77$ \\
\hline Yes, still on treatment & 3.11 & $2.85,3.39$ & 9.53 & $8.27,10.98$ \\
\hline \multicolumn{5}{|l|}{ Hypertension } \\
\hline Yes, but no treatment now & 1.11 & $1.09,1.12$ & 1.16 & $1.13,1.19$ \\
\hline Yes, still on treatment & 1.93 & $1.89,1.98$ & 3.38 & $3.24,3.53$ \\
\hline \multicolumn{5}{|l|}{ Diabetes } \\
\hline Yes, but no treatment now & 1.23 & $1.19,1.27$ & 1.51 & $1.42,1.60$ \\
\hline Yes, still on treatment (No insulin) & 2.88 & $2.75,3.03$ & 6.51 & $6.00,7.06$ \\
\hline Yes, still on treatment (Use insulin) & 3.81 & $3.36,4.32$ & 10.01 & $8.24,12.16$ \\
\hline \multicolumn{5}{|l|}{ Respiratory diseases } \\
\hline \multicolumn{5}{|l|}{ TB } \\
\hline Yes, but no treatment now & 1.44 & $1.37,1.52$ & 1.82 & $1.67,1.98$ \\
\hline Yes, still on treatment & 3.25 & $2.42,4.36$ & 7.53 & $4.49,12.62$ \\
\hline \multicolumn{5}{|l|}{ Emphysema/bronchitis } \\
\hline Yes, but no treatment now & 2.08 & $1.98,2.18$ & 3.34 & $3.09,3.62$ \\
\hline Yes, still on treatment & 4.02 & $3.69,4.38$ & 8.10 & $7.08,9.26$ \\
\hline \multicolumn{5}{|l|}{ Asthma } \\
\hline Yes, but no treatment now & 1.59 & $1.43,1.77$ & 2.42 & $2.02,2.89$ \\
\hline Yes, still on treatment & 3.69 & $3.06,4.46$ & 8.21 & $6.14,10.97$ \\
\hline \multicolumn{5}{|l|}{ Musculoskeletal diseases } \\
\hline \multicolumn{5}{|l|}{ Fracture } \\
\hline Yes, but no treatment now & 1.10 & $1.07,1.12$ & 1.18 & $1.13,1.23$ \\
\hline Yes, still on treatment & 1.27 & $1.13,1.43$ & 1.75 & $1.43,2.13$ \\
\hline \multicolumn{5}{|l|}{ Rheumatoid arthritis } \\
\hline Yes, but no treatment now & 1.63 & $1.54,1.71$ & 2.19 & $2.02,2.38$ \\
\hline Yes, still on treatment & 2.64 & $2.40,2.90$ & 4.90 & $4.23,5.67$ \\
\hline \multicolumn{5}{|l|}{ Mental diseases } \\
\hline \multicolumn{5}{|l|}{ Psychiatric disorders } \\
\hline Yes, but no treatment now & 1.72 & $1.50,1.97$ & 3.34 & $2.64,4.23$ \\
\hline Yes, still on treatment & 3.00 & $2.53,3.56$ & 8.95 & $6.40,12.52$ \\
\hline \multicolumn{5}{|l|}{ Neurasthenia } \\
\hline Yes, but no treatment now & 1.90 & $1.77,2.03$ & 2.69 & $2.42,2.99$ \\
\hline Yes, still on treatment & 3.49 & $2.99,4.07$ & 6.93 & $5.39,8.90$ \\
\hline
\end{tabular}


Table 13 Treatment associated with self-rated health status (Continued)

\begin{tabular}{|c|c|c|c|c|}
\hline & \multicolumn{2}{|c|}{ Global SRH (Total $n=512,889)$} & \multicolumn{2}{|c|}{ Age-comparative SRH (Total $n=175,980)$} \\
\hline & OR & $95 \% \mathrm{Cl}$ & OR & $95 \% \mathrm{Cl}$ \\
\hline \multicolumn{5}{|l|}{ Digestive diseases } \\
\hline \multicolumn{5}{|l|}{ Cirrhosis/chronic hepatitis } \\
\hline Yes, but no treatment now & 1.53 & $1.44,1.62$ & 2.25 & $2.02,2.50$ \\
\hline Yes, still on treatment & 3.92 & $3.25,4.73$ & 13.28 & $9.25,19.06$ \\
\hline \multicolumn{5}{|l|}{ Peptic ulcer } \\
\hline Yes, but no treatment now & 1.52 & $1.47,1.58$ & 2.08 & $1.97,2.20$ \\
\hline Yes, still on treatment & 2.82 & $2.61,3.05$ & 5.57 & $4.90,6.32$ \\
\hline \multicolumn{5}{|l|}{ Gallstone/gallbladder disease } \\
\hline Yes, but no treatment now & 1.51 & $1.47,1.56$ & 2.03 & $1.94,2.13$ \\
\hline Yes, still on treatment & 2.09 & $1.95,2.24$ & 3.22 & $2.87,3.60$ \\
\hline \multicolumn{5}{|l|}{ Cancer } \\
\hline Yes, but no treatment now & 2.16 & $1.94,2.40$ & 5.70 & $4.80,6.78$ \\
\hline Yes, still on treatment & 5.30 & $4.20,6.68$ & 13.72 & $9.48,19.86$ \\
\hline \multicolumn{5}{|l|}{ Other diseases } \\
\hline \multicolumn{5}{|l|}{ Kidney disease } \\
\hline Yes, but no treatment now & 1.44 & $1.36,1.52$ & 1.93 & $1.77,2.11$ \\
\hline Yes, still on treatment & 3.21 & $2.76,3.74$ & 4.80 & $3.85,5.98$ \\
\hline \multicolumn{5}{|l|}{ Head injury } \\
\hline Yes, but no treatment now & 1.17 & $1.11,1.24$ & 1.49 & $1.35,1.63$ \\
\hline Yes, still on treatment & 2.27 & $1.62,3.17$ & 7.72 & $4.08,14.62$ \\
\hline
\end{tabular}

Abbreviations: $\mathrm{Cl}$ confidence intervals, $O R$ odds ratio

The reference group are those who not suffering from the disease

Odds ratios $(95 \% \mathrm{Cl})$ were calculated after adjustment of age, sex, study location, marital status, household income, education level, occupation, alcohol drinking, cigarette smoking, physical activity, BMI, family history of five diseases (stroke, heart attack, diabetes, mental disorders and cancer) and all comorbidities Depressive Symptoms is not presented because the diseases is diagnosed on this investigation 
Table 14 Disease diagnosis time associated with self-rated health status

\begin{tabular}{|c|c|c|c|c|}
\hline \multirow{3}{*}{ Cardiometabolic diseases } & \multicolumn{2}{|c|}{ Global SRH (Total $n=512,889)$} & \multicolumn{2}{|c|}{ Age-comparative SRH (Total $n=175,980)$} \\
\hline & $\mathrm{OR}$ & $95 \% \mathrm{Cl}$ & $\mathrm{OR}$ & $95 \% \mathrm{Cl}$ \\
\hline & \multicolumn{4}{|c|}{ Cardiometabolic diseases } \\
\hline \multicolumn{5}{|l|}{ Coronary heart disease } \\
\hline Yes, diagnosis time $<10$ years & 2.67 & $2.53,2.81$ & 5.07 & $4.69,5.49$ \\
\hline Yes, diagnosis time $\geq 10$ years & 2.02 & $1.88,2.17$ & 2.83 & $2.54,3.15$ \\
\hline \multicolumn{5}{|l|}{ Rheumatic heart disease } \\
\hline Yes, diagnosis time $<10$ years & 4.31 & $3.03,6.13$ & 9.71 & $5.63,16.75$ \\
\hline Yes, diagnosis time $\geq 10$ years & 2.88 & $2.34,3.55$ & 5.28 & $3.88,7.19$ \\
\hline \multicolumn{5}{|l|}{ Stroke } \\
\hline Yes, diagnosis time $<10$ years & 3.08 & $2.89,3.29$ & 7.99 & $7.25,8.82$ \\
\hline Yes, diagnosis time $\geq 10$ years & 1.89 & $1.67,2.14$ & 4.51 & $3.75,5.43$ \\
\hline \multicolumn{5}{|l|}{ Hypertension } \\
\hline Yes, diagnosis time $<10$ years & 1.21 & $1.19,1.22$ & 1.39 & $1.35,1.42$ \\
\hline Yes, diagnosis time $\geq 10$ years & 1.89 & $1.82,1.97$ & 3.04 & $2.85,3.25$ \\
\hline \multicolumn{5}{|l|}{ Diabetes } \\
\hline Yes, diagnosis time $<10$ years & 1.67 & $1.62,1.71$ & 2.71 & $2.59,2.84$ \\
\hline Yes, diagnosis time $\geq 10$ years & 2.99 & $2.72,3.29$ & 6.69 & $5.77,7.76$ \\
\hline \multicolumn{5}{|l|}{ Respiratory diseases } \\
\hline \multicolumn{5}{|l|}{ TB } \\
\hline Yes, diagnosis time $<10$ years & 2.22 & $1.97,2.50$ & 3.94 & $3.20,4.84$ \\
\hline Yes, diagnosis time $\geq 10$ years & 1.35 & $1.28,1.43$ & 1.61 & $1.47,1.76$ \\
\hline \multicolumn{5}{|l|}{ Emphysema/bronchitis } \\
\hline Yes, diagnosis time $<10$ years & 2.78 & $2.60,2.97$ & 5.33 & $4.79,5.93$ \\
\hline Yes, diagnosis time $\geq 10$ years & 2.28 & $2.16,2.41$ & 3.69 & $3.38,4.02$ \\
\hline \multicolumn{5}{|l|}{ Asthma } \\
\hline Yes, diagnosis time $<10$ years & 2.57 & $2.16,3.07$ & 4.12 & $3.18,5.34$ \\
\hline Yes, diagnosis time $\geq 10$ years & 1.89 & $1.70,2.10$ & 3.43 & $2.87,4.09$ \\
\hline \multicolumn{5}{|l|}{ Musculoskeletal diseases } \\
\hline \multicolumn{5}{|l|}{ Fracture } \\
\hline Yes, diagnosis time $<10$ years & 1.12 & $1.09,1.16$ & 1.25 & $1.19,1.33$ \\
\hline Yes, diagnosis time $\geq 10$ years & 1.08 & $1.05,1.12$ & 1.13 & $1.06,1.19$ \\
\hline \multicolumn{5}{|l|}{ Rheumatoid arthritis } \\
\hline Yes, diagnosis time $<10$ years & 1.84 & $1.75,1.92$ & 2.70 & $2.51,2.90$ \\
\hline \multicolumn{5}{|l|}{ Mental diseases } \\
\hline \multicolumn{5}{|l|}{ Psychiatric disorders } \\
\hline Yes, diagnosis time $<10$ years & 2.54 & $2.12,3.05$ & 6.91 & $4.86,9.81$ \\
\hline Yes, diagnosis time $\geq 10$ years & 1.99 & $1.75,2.27$ & 4.20 & $3.35,5.26$ \\
\hline \multicolumn{5}{|l|}{ Neurasthenia } \\
\hline Yes, diagnosis time $<10$ years & 2.73 & $2.43,3.06$ & 4.87 & $4.08,5.82$ \\
\hline Yes, diagnosis time $\geq 10$ years & 1.91 & $1.78,2.06$ & 2.64 & $2.36,2.97$ \\
\hline \multicolumn{5}{|l|}{ Digestive diseases } \\
\hline \multicolumn{5}{|l|}{ Cirrhosis/chronic hepatitis } \\
\hline Yes, diagnosis time $<10$ years & 2.10 & $1.91,2.32$ & 3.95 & $3.32,4.68$ \\
\hline Yes, diagnosis time $\geq 10$ years & 1.49 & $1.39,1.60$ & 2.23 & $1.97,2.52$ \\
\hline
\end{tabular}


Table 14 Disease diagnosis time associated with self-rated health status (Continued)

\begin{tabular}{|c|c|c|c|c|}
\hline & \multicolumn{2}{|c|}{ Global SRH (Total $n=512,889)$} & \multicolumn{2}{|c|}{ Age-comparative SRH (Total $n=175,980)$} \\
\hline & $\mathrm{OR}$ & $95 \% \mathrm{Cl}$ & $\mathrm{OR}$ & $95 \% \mathrm{Cl}$ \\
\hline \multicolumn{5}{|l|}{ Peptic ulcer } \\
\hline Yes, diagnosis time $<10$ years & 1.96 & $1.87,2.06$ & 3.29 & $3.04,3.57$ \\
\hline Yes, diagnosis time $\geq 10$ years & 1.51 & $1.45,1.57$ & 2.03 & $1.90,2.17$ \\
\hline \multicolumn{5}{|l|}{ Gallstone/gallbladder disease } \\
\hline Yes, diagnosis time $<10$ years & 1.66 & $1.61,1.71$ & 2.36 & $2.23,2.48$ \\
\hline Yes, diagnosis time $\geq 10$ years & 1.46 & $1.40,1.52$ & 1.88 & $1.76,2.01$ \\
\hline \multicolumn{5}{|l|}{ Cancer } \\
\hline Yes, diagnosis time $<10$ years & 3.06 & $2.72,3.45$ & 8.60 & $7.05,10.48$ \\
\hline Yes, diagnosis time $\geq 10$ years & 1.76 & $1.49,2.08$ & 3.57 & $2.76,4.61$ \\
\hline \multicolumn{5}{|l|}{ Other diseases } \\
\hline \multicolumn{5}{|l|}{ Kidney disease } \\
\hline Yes, diagnosis time $<10$ years & 1.75 & $1.64,1.87$ & 2.36 & $2.14,2.61$ \\
\hline Yes, diagnosis time $\geq 10$ years & 1.44 & $1.33,1.56$ & 2.13 & $1.87,2.43$ \\
\hline \multicolumn{5}{|l|}{ Head injury } \\
\hline Yes, diagnosis time $<10$ years & 1.23 & $1.13,1.34$ & 1.56 & $1.35,1.80$ \\
\hline Yes, diagnosis time $\geq 10$ years & 1.16 & $1.08,1.25$ & 1.52 & $1.35,1.72$ \\
\hline
\end{tabular}

Abbreviations: $\mathrm{Cl}$ confidence intervals, OR odds ratio

The reference group are those who not suffering from the disease

Odds ratios $(95 \% \mathrm{Cl})$ were calculated after adjustment of age, sex, study location, marital status, household income, education level, occupation, alcohol drinking, cigarette smoking, physical activity, BMI family history of five diseases (stroke, heart attack, diabetes, mental disorders and cancer) and all comorbidities Depressive Symptoms is not presented because the disease is diagnosed on this investigation

Table 15 The number of diseases associated with self-rated health status

\begin{tabular}{llllc}
\hline & \multicolumn{2}{l}{ Global SRH (Total $n=512,889)$} & & Age-comparative SRH (Total $n=175,980)$ \\
& OR & $95 \% \mathrm{Cl}$ & OR & $95 \% \mathrm{Cl}$ \\
\hline Number of diseases & 1.44 & $1.42,1.46$ & 2.13 & $2.07,2.18$ \\
$\quad$ One disease & 2.37 & $2.32,2.42$ & 5.15 & $4.98,5.33$ \\
Two diseases & 3.91 & $3.76,4.07$ & 10.50 & $9.88,11.16$ \\
Three diseases & 6.45 & $5.96,6.98$ & 20.39 & $18.30,22.71$ \\
$\quad$ Four or more diseases & & & & \\
\hline
\end{tabular}

Abbreviations: $\mathrm{Cl}$ confidence intervals, $O R$ odds ratio

The reference group are those who not suffering from the disease

Odds ratios $(95 \% \mathrm{Cl})$ were calculated after adjustment of age, sex, study location, marital status, household income, education level, occupation, alcohol drinking, cigarette smoking, physical activity, BMI and family history of five diseases (stroke, heart attack, diabetes, mental disorders and cancer) 
Table 16 The site of cancer associated with self-rated health status

\begin{tabular}{|c|c|c|c|c|}
\hline & \multicolumn{2}{|c|}{ Global SRH (Total $n=512,889)$} & \multicolumn{2}{|c|}{ Age-comparative SRH (Total $n=175,980)$} \\
\hline & OR & $95 \% \mathrm{Cl}$ & OR & $95 \% \mathrm{Cl}$ \\
\hline \multicolumn{5}{|l|}{ Cancer site } \\
\hline lung & 3.38 & $2.15,5.33$ & 8.31 & $4.08,16.96$ \\
\hline esophagus & 2.26 & $1.71,3.00$ & 8.94 & $5.43,14.74$ \\
\hline stomach & 2.94 & $2.17,4.00$ & 7.79 & $4.72,12.86$ \\
\hline liver & 3.85 & $1.48,10.01$ & 7.15 & $2.28,22.41$ \\
\hline intestine & 2.35 & $1.78,3.10$ & 5.66 & $3.59,8.94$ \\
\hline breast & 2.31 & $1.90,2.81$ & 5.94 & $4.34,8.14$ \\
\hline cervix & 2.30 & $1.78,2.99$ & 3.70 & $2.45,5.59$ \\
\hline other & 2.94 & $2.40,3.61$ & 7.38 & $5.41,10.07$ \\
\hline
\end{tabular}

Abbreviations: $\mathrm{Cl}$ confidence intervals, $O R$ odds ratio

The reference group are those who not suffering from this cancer

Odds ratios $(95 \% \mathrm{Cl})$ were calculated after adjustment of age, sex, study location, marital status, household income, education level, occupation, alcohol drinking, cigarette smoking, physical activity, BMI, family history of five disease (stroke, heart attack, diabetes, mental disorders and cancer) and all comorbidities

Table 17 Multiple comorbidities associated with global and age-comparative self-rated health status: sensitivity analysis of using self-reported hypertension and diabetes

\begin{tabular}{|c|c|c|c|c|}
\hline & \multicolumn{2}{|c|}{$\begin{array}{l}\text { Global SRH } \\
\text { (Total } n=512,889 \text { ) }\end{array}$} & \multicolumn{2}{|c|}{ Age-comparative SRH (Total $n=175,980$ ) } \\
\hline & $\overline{\mathrm{OR}}$ & $95 \% \mathrm{Cl}$ & $\overline{\mathrm{OR}}$ & $95 \% \mathrm{Cl}$ \\
\hline \multicolumn{5}{|l|}{ Main analysis } \\
\hline Hypertension & 1.25 & $1.23,1.26$ & 1.47 & $1.44,1.51$ \\
\hline Diabetes & 1.77 & $1.72,1.82$ & 3.03 & $2.89,3.16$ \\
\hline \multicolumn{5}{|l|}{ Sensitivity analysis } \\
\hline Hypertension & 1.83 & $1.79,1.86$ & 3.08 & $2.97,3.20$ \\
\hline Diabetes & 2.80 & $2.69,2.92$ & 6.07 & $5.67,6.50$ \\
\hline
\end{tabular}

Abbreviations: $\mathrm{Cl}$ confidence intervals, $\mathrm{OR}$ odds ratio

Odds ratios $(95 \% \mathrm{Cl})$ were calculated after adjustment of age, sex, study location, marital status, household income, education level, occupation, alcohol drinking, cigarette smoking, physical activity, BMI, family history of five disease (stroke, heart attack, diabetes, mental disorders and cancer) and all comorbidities

\section{Abbreviations}

BMI: Body mass index; CHD: Coronary heart disease; Cl: Confidence intervals; CIDI-SF: Composite International Diagnostic Inventory — short form; CKB: China Kadoorie Biobank; METs: Metabolic equivalent tasks; OR: Odds ratio; PARs: Population attributable risks; SRH: Self-rated health

\section{Acknowledgements}

The chief acknowledgment is to the participants, the project staff, and the China National Centre for Disease Control and Prevention (CDC) and its regional offices for assisting with the fieldwork. We thank Judith Mackay in Hong Kong; Yu Wang, Gonghuan Yang, Zhengfu Qiang, Lin Feng, Maigeng Zhou, Wenhua Zhao, and Yan Zhang in China CDC; Lingzhi Kong, Xiucheng $\mathrm{Yu}$, and Kun Li in the Chinese Ministry of Health; and Sarah Clark, Martin Radley, Mike Hill, Hongchao Pan, and Jill Boreham in the CTSU, Oxford, for assisting with the design, planning, organization, and conduct of the study. Members of the China Kadoorie Biobank collaborative group. International Steering Committee: Junshi Chen, Zhengming Chen (PI), Rory Collins, Liming Li (PI), Richard Peto. International Coordinating Center, Oxford: Daniel Avery, Ruth Boxall, Derrick Bennett, Yumei Chang, Yiping Chen, Zhengming Chen, Robert Clarke, Huaidong Du, Simon Gilbert, Alex Hacker, Mike Hill, Michael Holmes, Andri lona, Christiana Kartsonaki; Rene Kerosi, Ling Kong, Om Kurmi, Garry Lancaster, Sarah Lewington, Kuang Lin, John McDonnell, Iona Millwood, Qunhua Nie, Jayakrishnan Radhakrishnan,
Sajjad Rafiq, Paul Ryder, Sam Sansome, Dan Schmidt, Paul Sherliker, Rajani Sohoni, Becky Stevens, lain Turnbull, Robin Walters, Jenny Wang, Lin Wang, Neil Wright, Ling Yang, Xiaoming Yang. National Coordinating Center, Beijing: Zheng Bian, Yu Guo, Xiao Han, Can Hou, Jun Lv, Pei Pei, Yunlong Tan, Canqing Yu. 10 Regional Coordinating Centers: Qingdao CDC: Zengchang Pang, Ruqin Gao, Shanpeng Li, Shaojie Wang, Yongmei Liu, Ranran Du, Yajing Zang, Liang Cheng, Xiaocao Tian, Hua Zhang, Yaoming Zhai, Feng Ning, Xiaohui Sun, Feifei Li. Licang CDC: Silu LV, Junzheng Wang, Wei Hou. Heilongjiang Provincial CDC: Mingyuan Zeng, Ge Jiang, Xue Zhou. Nangang CDC: Liqiu Yang, Hui He, Bo Yu, Yanjie Li, Qinai Xu,Quan Kang, Ziyan Guo. Hainan Provincial CDC: Dan Wang, Ximin Hu, Hongmei Wang, Jinyan Chen, Yan Fu, Zhenwang Fu, Xiaohuan Wang. Meilan CDC: Min Weng, Zhendong Guo, Shukuan Wu,Yilei Li, Huimei Li, Zhifang Fu. Jiangsu Provincial CDC: Ming Wu, Yonglin Zhou, Jinyi Zhou, Ran Tao, Jie Yang, Jian Su. Suzhou CDC: Fang liu, Jun Zhang, Yihe Hu, Yan Lu, Liangcai Ma, Aiyu Tang, Shuo Zhang, Jianrong Jin, Jingchao Liu. Guangxi Provincial CDC: Zhenzhu Tang, Naying Chen, Ying Huang. Liuzhou CDC: Mingqiang Li, Jinhuai Meng, Rong Pan, Qilian Jiang, Jian Lan,Yun Liu, Liuping Wei, Liyuan Zhou, Ningyu Chen Ping Wang, Fanwen Meng, Yulu Qin, Sisi Wang. Sichuan Provincial CDC: Xianping Wu, Ningmei Zhang, Xiaofang Chen,Weiwei Zhou. Pengzhou CDC: Guojin Luo, Jianguo Li, Xiaofang Chen, Xunfu Zhong, Jiaqiu Liu, Qiang Sun. Gansu Provincial CDC: Pengfei Ge, Xiaolan Ren, Caixia Dong. Maiji CDC: Hui Zhang, Enke Mao, Xiaoping Wang, Tao Wang, Xi zhang. 
Henan Provincial CDC: Ding Zhang, Gang Zhou, Shixian Feng, Liang Chang, Lei Fan. Huixian CDC: Yulian Gao, Tianyou He, Huarong Sun, Pan He, Chen Hu, Xukui Zhang, Huifang Wu, Pan He. Zhejiang Provincial CDC: Min Yu, Ruying Hu, Hao Wang. Tongxiang CDC: Yijian Qian, Chunmei Wang, Kaixu Xie, Lingli Chen, Yidan Zhang, Dongxia Pan, Qijun Gu. Hunan Provincial CDC: Yuelong Huang, Biyun Chen, Li Yin „, Huilin Liu, Zhongxi Fu, Qiaohua Xu. Liuyang CDC: Xin Xu, Hao Zhang, Huajun Long, Xianzhi Li, Libo Zhang, Zhe Qiu.

\section{Funding}

This work was supported by the National Key Research and Development Program of China (2016YFC0900500, 2016YFC0900501, 2016YFC0900504, 2017 YFC0907500 and 2017YFC0907504) and the National Natural Science Foundation of China (81390540, 81390541, and 81202266). The CKB baseline survey and the first re-survey were supported by a grant from the Kadoorie Charitable Foundation in Hong Kong. The long-term follow-up is supported by grants from the UK Wellcome Trust (202922/Z/16/Z, 088158/Z/09/Z, 104085/Z/14/Z) and Chinese Ministry of Science and Technology (2011BAl09B01). The funders had no role in the study design, data collection, data analysis and interpretation, writing of the report, or the decision to submit the article for publication.

\section{Availability of data and materials}

The data that support the findings of this article are available from the CKB upon reasonable request (http://www.ckbiobank.org/site/Data+Access).

\section{Authors' contributions}

CQY, JL, YG, ZMC and LML designed the study and directed its implementation, including quality assurance and control, dataset management and analytic strategy. ZB, LY, and YPC helped supervise the field activities and designed the study's analytic strategy. XYS and JW analyzed the data and prepared the manuscript. AP and WHD helped with results interpretation. All authors have critically commented on and revised the manuscript, and approved the final version. AP and LML are guarantors of the paper.

\section{Ethics approval and consent to participate}

The study got approval from the ethical review committees of the Chinese Center for Disease Control and Prevention (Beijing, China) and the Oxford Tropical Research Ethics Committee, University of Oxford (UK). Written informed consent forms were obtained from all participants.

\section{Competing interests}

The authors declare that they have no competing interests.

\section{Publisher's Note}

Springer Nature remains neutral with regard to jurisdictional claims in published maps and institutional affiliations.

\section{Author details}

'Department of Epidemiology and Biostatistics, and Ministry of Education Key Laboratory of Environment and Health, and State Key Laboratory of Environmental Health (Incubating), School of Public Health, Tongji Medical College, Huazhong University of Science and Technology, 13 Hangkong Rd, Wuhan 430030, China. ${ }^{2}$ Department of Epidemiology and Biostatistics, School of Public Health, Peking University Health Science Center, 38 Xueyuan Rd, Beijing 100191, China. ${ }^{3}$ Chinese Academy of Medical Sciences, Dong Cheng District, Beijing, China. ${ }^{4}$ Clinical Trial Service Unit and Epidemiological Studies Unit (CTSU), Nuffield Department of Population Health, University of Oxford, Oxford, UK.

\section{Received: 9 March 2018 Accepted: 29 May 2018}

Published online: 15 June 2018

\section{References}

1. Verropoulou G. Specific versus general self-reported health indicators predicting mortality among older adults in Europe: disparities by gender employing SHARE longitudinal data. Int J Public Health. 2014;59(4):665-78.

2. DeSalvo KB, Bloser N, Reynolds K, He J, Muntner P. Mortality prediction with a single general self-rated health question. A meta-analysis. J Gen Intern Med. 2006;21(3):267-75.
3. Vuorisalmi M, Lintonen T, Jylha M. Comparative vs global self-rated health: associations with age and functional ability. Aging Clin Exp Res. 2006;18(3):211-7.

4. Eriksson I, Unden AL, Elofsson S. Self-rated health. Comparisons between three different measures. Results from a population study. Int J Epidemiol. 2001;30(2):326-33.

5. de Bruin A, Picavet HS, Nossikov A. Health interview surveys. Towards international harmonization of methods and instruments. WHO Reg Publ Eur Ser. 1996;58(i-xiii):1-161.

6. Idler EL, Benyamini Y. Self-rated health and mortality: a review of twentyseven community studies. J Health Soc Behav. 1997;38(1):21-37.

7. Ganna A, Ingelsson E. 5 year mortality predictors in 498,103 UK biobank participants: a prospective population-based study. Lancet. 2015;386(9993):533-40.

8. Harrington J, Perry IJ, Lutomski J, Fitzgerald AP, Shiely F, McGee H, Barry MM, Van Lente E, Morgan K, Shelley E. Living longer and feeling better: healthy lifestyle, self-rated health, obesity and depression in Ireland. Eur J Pub Health. 2010;20(1):91-5.

9. Jonnalagadda SS, Diwan S. Health behaviors, chronic disease prevalence and self-rated health of older Asian Indian immigrants in the U.S. J Immigr Health. 2005;7(2):75-83.

10. Pisinger $C$, Toft $U$, Aadahl M, Glumer $C$, Jorgensen T. The relationship between lifestyle and self-reported health in a general population the Inter99 study. Prev Med. 2009;49(5):418-23.

11. Popham F, Gray L, Bambra C. Employment status and the prevalence of poor self-rated health. Findings from UK individual-level repeated crosssectional data from 1978 to 2004. BMJ Open. 2012;2(6):e001342.

12. Roberts G. Age effects and health appraisal: a meta-analysis. J Gerontol B Psychol Sci Soc Sci. 1999;54(1):S24-30.

13. Li Y, Fu H, Zhao F, Luo JF, Kawachi I. Influence of spousal education on partner's self-rated health: cross-sectional study among 1382 married couples in shanghai, China. Asia Pac J Public Health. 2013;25(5):398-408.

14. Yu LC, Zhang AY, Draper P, Kassab C, Miles T. Cultural correlates of self perceived health status among Chinese elderly. J Cross Cult Gerontol. 1997:12(1):73-89.

15. Haseen F, Adhikari R, Soonthorndhada K. Self-assessed health among Thai elderly. BMC Geriatr. 2010;10:30.

16. Cheng ST, Chan AC. Social support and self-rated health revisited: is there a gender difference in later life? Soc Sci Med. 2006;63(1):118-22.

17. Bin Li Z, Lam TH, Ho SY, Chan WM, Ho KS, Li MP, Leung GM, Fielding R. Age-versus time-comparative self-rated health in Hong Kong Chinese older adults. Int J Geriatr Psychiatry. 2006;21(8):729-39.

18. Waller G, Janlert U, Hamberg K, Forssen A. What does age-comparative selfrated health measure? A cross-sectional study from the northern Sweden MONICA project. Scand J Public Health. 2016;44(3):233-9.

19. Chan YY, Teh CH, Lim KK, Lim KH, Yeo PS, Kee CC, Omar MA, Ahmad NA. Lifestyle, chronic diseases and self-rated health among Malaysian adults: results from the 2011 National Health and morbidity survey (NHMS). BMC Public Health. 2015;15:754.

20. Haseli-Mashhadi N, Pan A, Ye X, Wang J, Qi Q, Liu Y, Li H, Yu Z, Lin X, Franco $\mathrm{OH}$. Self-rated health in middle-aged and elderly Chinese: distribution, determinants and associations with cardio-metabolic risk factors. BMC Public Health. 2009;9:368.

21. Molarius A, Janson S. Self-rated health, chronic diseases, and symptoms among middle-aged and elderly men and women. J Clin Epidemiol. 2002;55(4):364-70.

22. Chen Z, Chen J, Collins R, Guo Y, Peto R, Wu F, Li L. China Kadoorie biobank of 0.5 million people: survey methods, baseline characteristics and long-term follow-up. Int J Epidemiol. 2011;40(6):1652-66.

23. Chen Z, Lee L, Chen J, Collins R, Wu F, Guo Y, Linksted P, Peto R. Cohort profile: the Kadoorie study of chronic disease in China (KSCDC). Int J Epidemiol. 2005;34(6):1243-9.

24. Bragg F, Li L, Yang L, Chen Y, Bian Z, Chen J, Collins R, Peto R, Wang C, et al. Risks and population burden of cardiovascular diseases associated with diabetes in China: a prospective study of 0.5 million adults. PLoS Med. 2016; 13(7):e1002026.

25. Lewington S, Lacey B, Clarke R, Guo Y, Kong XL, Yang L, Chen Y, Bian $Z$, Chen J, Meng J, et al. The burden of hypertension and associated risk for cardiovascular mortality in China. JAMA Intern Med. 2016;176(4):524-32. 
26. Mezuk B, Chen Y, Yu C, Guo Y, Bian Z, Collins R, Chen J, Pang Z, Wang H, Peto $R$, et al. Depression, anxiety, and prevalent diabetes in the Chinese population: findings from the China Kadoorie biobank of 0.5 million people. J Psychosom Res. 2013;75(6):511-7.

27. Kleinbaum DG, Kupper LL, Morgenstern H. Epidemiologic Research: Principles and quantitative methods. London: Lifetime Learning; 1982.

28. Lim WY, Ma S, Heng D, Bhalla V, Chew SK. Gender, ethnicity, health behaviour \& self-rated health in Singapore. BMC Public Health. 2007;7:184.

29. Cau BM, Falcao J, Arnaldo C. Determinants of poor self-rated health among adults in urban Mozambique. BMC Public Health. 2016;16(1):856.

30. Alwindi A. The relations between symptoms, somatic and psychiatric conditions, life satisfaction and perceived health. A primary care based study. Health Qual Life Outcomes. 2005;3(1):1-9.

31. Cai J, Coyte PC, Zhao H. Determinants of and socio-economic disparities in self-rated health in China. Int J Equity Health. 2017:16(1):7.

32. Demirchyan A, Thompson ME. Determinants of self-rated health in women: a population-based study in Armavir Marz, Armenia, 2001 \& 2004. Int J Equity Health. 2008;7:25.

33. Banerjee C, Moon YP, Paik MC, Rundek T, Mora-McLaughlin C, Vieira JR, Sacco RL, Elkind MS. Duration of diabetes and risk of ischemic stroke: the northern Manhattan study. Stroke. 2012;43(5):1212-7.

34. Silbernagel G, Rosinger S, Grammer TB, Kleber ME, Winkelmann BR, Boehm BO, Marz W. Duration of type 2 diabetes strongly predicts all-cause and cardiovascular mortality in people referred for coronary angiography. Atherosclerosis. 2012;221(2):551-7.

35. O'Donnell MJ, Xavier D, Liu L, Zhang H, Chin SL, Rao-Melacini P, Rangarajan S, Islam S, Pais P, McQueen MJ, et al. Risk factors for ischaemic and intracerebral haemorrhagic stroke in 22 countries (the INTERSTROKE study): a case-control study. Lancet. 2010;376(9735):112-23.

36. Hoeymans N, Feskens EJ, Kromhout D, Ga VDB. The contribution of chronic conditions and disabilities to poor self-rated health in elderly men. J Gerontol A Biol Sci Med Sci. 1999;54(10):M501-6.

37. Lu J, Lu Y, Wang X, Li X, Linderman G, Wu C, Cheng X, Mu L, Zhang H, Liu J, et al. Prevalence, awareness, treatment, and control of hypertension in China: data from 1.7 million adults in a population-based screening study (China PEACE million persons project). Lancet. 2017;390(10112):2549-58.

38. Wang L, Gao P, Zhang M, Huang Z, Zhang D, Deng Q, Li Y, Zhao Z, Qin X, Jin $D$, et al. Prevalence and ethnic pattern of diabetes and Prediabetes in China in 2013. JAMA. 2017;317(24):2515-23.

39. Bond J, Dickinson HO, Matthews F, Jagger C, Brayne C. Self-rated health status as a predictor of death, functional and cognitive impairment: a longitudinal cohort study. Eur J Ageing. 2006;3(4):193-206.

\section{Ready to submit your research? Choose BMC and benefit from:}

- fast, convenient online submission

- thorough peer review by experienced researchers in your field

- rapid publication on acceptance

- support for research data, including large and complex data types

- gold Open Access which fosters wider collaboration and increased citations

- maximum visibility for your research: over $100 \mathrm{M}$ website views per year

At BMC, research is always in progress.

Learn more biomedcentral.com/submissions 